\title{
Ordered mesoporous titania from highly amphiphilic block copolymers: tuned solution conditions enable highly ordered morphologies and ultra-large mesopores
}

\author{
Morgan Stefik $_{5}^{1 \S *}$, Juho Song ${ }^{2,3 \S}$, Hiroaki Sai $^{2}$, Stefan Guldin ${ }^{4}$, Patrick Boldrighini ${ }^{2}$, M. Christopher Orilall ${ }^{2}$, Ullrich \\ Steiner ${ }^{5}$, Sol M. Gruner ${ }^{6}$, Ulrich Wiesner ${ }^{2} *$ \\ ${ }^{1}$ Department Chemistry and Biochemistry, University of South Carolina, Columbia, SC 29208. \\ ${ }^{2}$ Department of Materials Science and Engineering, Cornell University, Ithaca, New York 14853. \\ ${ }^{3}$ School of Chemical and Biomolecular Engineering, Cornell University, Ithaca, New York 14853 \\ ${ }^{4}$ Department of Chemical Engineering, University College London, Torrington Place, London, WC1E 7JE. \\ ${ }^{5}$ Adolphe Merkle Institute, University of Fribourg, Chemin des Verdiers, 1700 Fribourg, CH. \\ ${ }^{6}$ Department of Physics, Cornell University and Cornell High Energy Synchrotron Source, Ithaca, New York 14853. \\ $\S$ These authors contributed equally to this work \\ *e-mail: morgan@stefikgroup.com \\ *e-mail: ubw1@cornell.edu
}

\begin{abstract}
Crystalline transition metal oxides with controlled mesopore architectures are in increasing demand to enhance the performance of energy conversion and storage devices. Solution based block copolymer self-assembly routes to achieve ordered mesoporous and crystalline titania have been studied for more than a decade, but have so far mostly been limited to water and alcohol dispersible polymers. This constraint has limited the accessible morphology space as well as structural dimensions. Moreover, synthetic approaches are mostly performed in a trial-and-error fashion using chemical intuition rather than being based on well-defined design parameters. We present solubility design guidelines that facilitate coassembly with highly amphiphilic block copolymers, enabling the formation of ordered structures with diverse length scales $\left(\mathrm{d}_{10}=13.8-63.0 \mathrm{~nm}\right)$ and bulk-type morphologies. Thus, highly ordered and crystalline titania with the largest reported pores $(\mathrm{d}=32.3 \mathrm{~nm})$ was demonstrated for such a coassembly approach without the use of poreexpanders. Furthermore, the use of an ABC triblock terpolymer system led to a 3D ordered network morphology. In all cases, subsequent calcination treatments, such as the CASH procedure, enabled the formation of highly crystalline mesoporous materials while preserving the mesostructure.
\end{abstract}

\section{Introduction}

Significant efforts have focused on the control of transition metal oxide nanostructures which have a diverse range of (photo)catalytic, transport (electron/ion), electronic (insulator/semiconductor/conductor), and optical properties. Indeed, transition metal oxide nanostructures are of great interest for numerous applications including, e.g., batteries, supercapacitors, dye-sensitized solar cells, photoelectrochemical water splitting devices, fuel cells, and electrochromic devices. ${ }^{1-9}$ For all of the above catalysis and electrochemistry uses, the material performance is largely dictated by the nature and availability of surfaces. Thus the role of morphology on the nanoscale plays a significant role on device performance. Among the many transition metal oxides, titania is one of the most popular due to its use in the whole range of applications mentioned above. ${ }^{10,11}$

Over the past two decades significant advances have been made in the fabrication of ordered inorganic materials with organic structure-directing agents (SDA). Typically amphiphilic SDAs are used where a selective interaction such as electrostatics or hydrogen bonding selectively associate the hydrophilic inorganic entities with the hydrophilic portion of the SDA. At the same time, the hydrophobic portion of the SDA phase separates from the hydrophilic components with nanoscale periodicity. Under certain controlled conditions the free energy balance of the inorganic-SDA coassembly leads to the equilibration of highly ordered nanoscale domains. The first example of such an approach utilized a surfactant to swell the spacing between ordered kanemite sheets in $1990^{12}$. This concept was then greatly expanded to enable the assembly of other silicate materials with multiple ordered morphologies by utilizing micellar surfactant assemblies. $^{13}$

The controlled coassembly of transition metal oxides with SDAs is more difficult than silicates due to the multiple stable coordination states and much greater chemical reactivity (e.g. hydrolysis of $\mathrm{Ti}(\mathrm{OR})_{4}$ is $10^{5}$ times faster than $\left.\mathrm{Si}(\mathrm{OR})_{4}\right) .{ }^{14}$ Hydrolytic sol-gel routes were typically employed under acidic conditions that promote hydrolysis and severely slow the condensation reactions to allow time for coassembly with the SDA before gelation. Chelating ligands and non-hydrolytic sol-gel approaches have also been employed to slow these reaction rates. Although metal oxides other than titania were first accomplished, ${ }^{15}$ similar methodologies later yielded ordered titania nanostructures. ${ }^{16}$ Often the SDAs were removed from such hybrid materials to yield micro/mesoporous materials (IUPAC pore-size naming 
convention $^{17,}{ }^{18}$ ) preserving the ordered inorganic morphology. The pore sizes in surfactant-based materials were typically $\sim 1-5 \mathrm{~nm}$ due to the small molar mass of the SDA $(\sim 150-350 \mathrm{~g} / \mathrm{mol})$. This limited range of pore sizes was expanded up to $\sim 7 \mathrm{~nm}$ for ordered pores and up to 12 $\mathrm{nm}$ for irregular pores by swelling the hydrophobic domains with hydrophobic "pore-expanding" molecules. ${ }^{19}$

Amphiphilic block copolymers are able to circumvent this feature size limitation with larger SDA molar masses $(\sim 1,000-70,000 \mathrm{~g} / \mathrm{mol})$. Most block copolymer SDAs utilize a non-ionic poly(ethylene oxide) block to coordinate with the inorganic species. ${ }^{20,}$ Block copolymers were first applied in the structure-directed manufacture of ordered silicates ${ }^{22,23}$ and were then employed as SDAs with many transition metal oxides, including titania. $^{24}$ Pluronic poly(ethylene oxide- $b$ propylene oxide- $b$-ethylene oxide), (PEO- $b$-PPO- $b$-PEO)s are commercially available and thus commonly used polymers of relatively low molar mass, $\sim 2,000-13,000$ $\mathrm{g} / \mathrm{mol}^{25}$ (Table I). It follows that the resulting ordered oxide structures typically had 4-7 nm pores which were only slightly larger than those obtained from conventional surfactants. Similar to surfactants, larger pores were observed in disordered films ${ }^{26}$ or when pore expanders

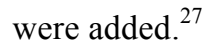

Many applications utilizing transition metal oxides require the electronic or catalytic properties of specific crystal structures. Thus, significant effort was directed towards crystallization heat treatments of the amorphous transition metal oxide structures that typically result from hydrolytic sol-gel processes. Such heat treatments of titania films structure-directed with Pluronics are typically limited to low temperatures which result in anatase crystallites embedded in amorphous walls. ${ }^{24}$ Although Pluronic SDAs can lead to highly crystalline ordered titania nanostructures when supported thin films were calcined, there remains a general challenge to achieve highly crystalline and ordered bulk materials. ${ }^{28-30}$ Successful crystallization requires the good interconnection of amorphous oxide particles and resulting crystallite sizes that are comparable to the wall thickness.

An alternative polymeric SDA is based on hydrogenated poly(butadiene- $b$-ethylene oxide) and is termed KLE. It yields mesoporous materials with thicker walls that enabled higher temperature processing which resulted in larger crystallites and reduced amorphous content. For example, KLE led to mesoporous titania thin films with $10 \mathrm{~nm}$ pores that were stable up to $600{ }^{\circ} \mathrm{C} .{ }^{31,32} \mathrm{KLE}$ polymers have similar molar masses as Pluronics, but have a much larger Flory-Huggins monomer-monomer interaction parameter, $\chi$. The resulting increased enthalpic penalty for A-B interfacial contacts between the KLE blocks offsets the entropic penalty for chain stretching, leading to slightly larger mesostructures than Pluronic polymers. However, only spherical micellar morphologies have been demonstrated with KLE SDAs thus far. ${ }^{31-33}$ There are indeed numerous reports of coassembled titania with block copolymers. ${ }^{3,16,24,26-58}$
The achievement of larger nanostructures and/or novel ordered morphologies requires the development of new structure-directing agents. ${ }^{59}$ The combination of creative polymer chemistry with inorganic/solid-state chemistry is likely to ultimately yield the biggest benefits for SDAbased approaches. Most polymers are hydrophobic, however, and are thus immiscible with the typically used alcohol and water based sol-gel processes (in fact water and alcohol are commonly used as precipitation agents for polymers). The coassembly of titania with poly(styrene- $b$ ethylene oxide) (PS- $b$-PEO) in the presence of these poor solvents lead to either disordered structures ${ }^{55,60,61}$ or to ordered macroporous emulsions. ${ }^{62}$ Although PS- $b$-PEO has also coassembled ordered nanostructures under certain conditions, there is not yet a systematic framework for developing new coassembly systems with highly amphiphilic block copolymers. ${ }^{63-65}$ The formation of equilibrated bulk morphologies based on block copolymer thermodynamics requires that the polymer does not become trapped in a selective solvent-induced morphology such as spherical micelles. Another example are the $\sim 30,000 \mathrm{~g} / \mathrm{mol}$ and highly amphiphilic poly(isoprene- $b$-ethylene oxide)s (PI- $b$-PEO) with majority PI blocks which were recently used to structuredirect inverse-hexagonal niobium oxide and worm-like titania nanostructures. ${ }^{66}$ The use of non-hydrolytic sol-gel processes and organic solvents were key to enabling solvent evaporation-induced coassembly with these hydrophobic polymers. In the same study, the so called combined assembly by soft and hard (CASH) chemistries approach enabled oxide crystallization without structure collapse by the in-situ creation of a hard template from the carbon which resulted from polymer pyrolysis under an inert atmosphere. The carbon was subsequently removed, yielding crystalline oxide nanostructures with large $\sim 24 \mathrm{~nm}$ pores and $10 \mathrm{~nm}$ thick walls. While 8 different morphologies were demonstrated with PI- $b$-PEO SDAs in aluminosilicates, ${ }^{67}$ including bicontinuous networked structures, ${ }^{68-71}$ this morphological diversity is currently lacking in titania nanostructures. Finally, an emerging trend to achieve ordered network morphologies is based on ABC triblock terpolymer SDAs which have large composition windows for network coassembly. ${ }^{72}$ Here again, better control of the evaporation-induced structure formation is needed to fully realize the morphological diversity of triblock terpolymer selfassembly with transition metal oxides, including access to large pore mesoporous materials.

From all of the above examples, it is apparent that there is a need to develop a better understanding of the thermodynamic processes that control (transition metal) oxide structure formation directed from large molar mass SDAs in different solvents. In particular, it is desirable to establish quantitative, or at least semi-quantitative guidelines for successful structure formation, replacing chemical intuition-based trial and error. Toward this end, we provide a framework to semi-quantitatively describe the solvent evaporation-induced coassembly of titania into ordered bulk-type morphologies using highly amphiphilic block copolymers over a broad range of molecular weights. This framework, which is based on solubility parameters, provides experimental guidelines to 
avoid kinetically trapped solution structures (such as spherical micelles) thereby enabling the fine-tuning of titania nanostructures and pore sizes. This semiquantitative approach allowed us to achieve a highly ordered crystalline titania structure with the largest reported cylindrical mesopores to date without the use of pore-expanding agents. The extension of this approach from simple $\mathrm{AB}$ diblock copolymers to $\mathrm{ABC}$ triblock terpolymers with ordered network nanostructures suggests that this framework may be generalizable to other new SDAs.

\section{Experimental Procedures}

Reagents. Tetrahydrofuran (THF, HPLC grade, J.T. Baker) was stored over activated $3 \AA$ molecular sieves until use, or anhydrous tetrahydrofuran $(>99.9 \%$, Aldrich) was used as received. Titanium isopropoxide (97\%, Aldrich) and concentrated hydrochloric acid (37wt $\%$ ACS grade, BDH Aristar) were used as received. Block copolymers were prepared by anionic polymerization using reported procedures. ${ }^{73,74}$ Poly(isoprene- $b$-ethylene oxide)s (PI- $b$-PEO) were synthesized with different molar masses from 7 to $92 \mathrm{~kg} / \mathrm{mol}$. They are termed as IOxK, with $\mathrm{x}$ denoting the polymer molar mass in $\mathrm{kg} / \mathrm{mol}$. Characterization results are summarized in Table II. All polymers showed narrow molar mass distributions with PDIs (polydispersity index) less than 1.11. Poly(isoprene$b$-styrene- $b$-ethylene oxide) (ISO1) was synthesized as described elsewhere ${ }^{75}$ with a molar mass of $53.4 \mathrm{~kg} / \mathrm{mol}$ containing $14.6 \mathrm{~kg} / \mathrm{mol}$ of PI, $29.0 \mathrm{~kg} / \mathrm{mol}$ of PS, and 9.8 $\mathrm{kg} / \mathrm{mol}$ of PEO and a PDI of 1.05 .

Hybrid synthesis. Block copolymers were dissolved in THF with stirring for at least 1 hour. Hydrochloric acid was then added to the polymer solution followed by titanium isopropoxide. The resulting orange to red solution was stirred for $24 \mathrm{hrs}$ during which the solution turned slightly yellow to clear. The solution was cast into an $8 \mathrm{~cm}$ Teflon dish which was placed onto a glass dish on a hotplate to slow the loss of $\mathrm{HCl}$ due to reaction with the steel hotplate surface. This assembly was then covered with a glass hemisphere to slow evaporation and limit exposure to ambient humidity. The hot plate was set to 50 ${ }^{\circ} \mathrm{C}$ creating an effective casting temperature of $\sim 40{ }^{\circ} \mathrm{C}$. After $24 \mathrm{hrs}$ of drying, the films were placed into an oven set to $100{ }^{\circ} \mathrm{C}$ for a minimum of 3 days to enhance the condensation reaction. The films were then subjected to calcination heat treatments to crystallize the titania. Crystallization was induced either in air to oxidatively remove the polymer or in nitrogen to convert the polymer into a carbonaceous framework using the CASH approach, vide supra. The inverse hexagonal hybrids were heated to $700{ }^{\circ} \mathrm{C}$ and the networked hybrids were heated to $400{ }^{\circ} \mathrm{C}$. The carbon residue in some composites was subsequently removed by heating to $450{ }^{\circ} \mathrm{C}$ in air for at least 1 hour. All heat treatments utilized a $1-5{ }^{\circ} \mathrm{C} / \mathrm{min}$ heating ramp rate with a 1-4 hour hold followed by letting the furnace cool to room temperature.

As-made samples prepared with IO28K are termed IO28K-hx where $x$ is the $w t \%$ of water in the THF solution prior to addition of the titanium isopropoxide.
These casting solutions were all prepared with $50 \mathrm{mg}$ of IO28K, $0.119 \mathrm{~mL} \mathrm{HCl}(\mathrm{aq}), 0.371 \mathrm{~mL}$ titanium(IV) isopropoxide, and the quantity of THF required to yield $\mathrm{x}$ $\mathrm{wt} \%$ water in the solution. Thus $2.44,3.28,4.97$, and 9.27 $\mathrm{mL}$ of THF were used to prepare the samples IO28K-h4, IO28K-h3, IO28K-h2, and IO28K-h1 with 4.0, 3.0, 2.0 and 1.08 wt. $\%$ water, respectively. Note that the molar ratios for all recipes had $\mathrm{Ti}: \mathrm{H}_{2} \mathrm{O}: \mathrm{HCl}$ of $1.0: 4.0: 1.16$ which corresponds to the minimum water content required for the complete hydrolysis of the titanium alkoxide.

Pore size control experiments used different molar mass PI- $b$-PEOs and employed an ex-situ sol-gel route. $50 \mathrm{mg}$ of PI- $b$-PEO was dissolved in $8 \mathrm{ml}$ of THF with stirring for about 1 hour. A titanium-containing sol was prepared separately by the addition of $0.4 \mathrm{ml}$ titanium(IV) isopropoxide to $0.129 \mathrm{ml}$ hydrochloric acid (37\%) under vigorous stirring followed by addition of $2 \mathrm{ml}$ THF after 5 min stirring. After another $5 \mathrm{~min}$, the sol was added to the polymer solution followed by stirring for one hour. Then the films were cast and annealed as described before.

Hybrids from ISO1 were prepared similarly. $75 \mathrm{mg}$ of ISO1 was dissolved in $2.9 \mathrm{~mL}$ of dry THF with stirring for at least $1 \mathrm{hr}$. A dilute sol stock solution was prepared to enable accurate addition of a small quantity of titania: 5 $\mathrm{mL}$ of titanium isopropoxide was added to a quickly stirred vial containing $1.6 \mathrm{~mL}$ of concentrated $\mathrm{HCl}(\mathrm{aq})$. The vial was closed after combining alkoxide with acid and was left to stir for $5 \mathrm{~min}$ before $10 \mathrm{~mL}$ of dry THF was added to dilute the sol (orange color) and left to stir for an additional $2 \mathrm{~min}$. A syringe was used to immediately measure $0.388 \mathrm{~mL}$ of the dilute sol stock solution and the aliquot was added directly to the stirred polymer solution. This combined solution was left to stir for at least $30 \mathrm{~min}$ and was then cast as previously described for the IO28K-hx samples. After $24 \mathrm{hrs}$, the film was placed into an oven set to $100{ }^{\circ} \mathrm{C}$ for 3 days to enhance the condensation reaction. Portions of this film were calcined under different temperature and atmospheric conditions to optimize the crystallization process while preserving the ordered mesostructure. Samples ISO1-N $\mathrm{N}_{2}$ and ISO1-air were both prepared directly from sample ISO1- $\mathrm{TiO}_{2}$ by heating at $1{ }^{\circ} \mathrm{C} / \mathrm{min}$ to $400{ }^{\circ} \mathrm{C}$ with a $1 \mathrm{hr}$ hold followed by letting the furnace cool in $\mathrm{N}_{2}$ or air, respectively.

\section{Characterization}

TEM. Ultrathin $\sim 70 \mathrm{~nm}$ sections were prepared with wet cryo microtoming using a Leica UC7/FC7 cryoultramicrotome. Sections were cut at $-55{ }^{\circ} \mathrm{C}$ onto a $60: 40$ dimethylsulfoxide : water solution and then transferred to bare copper grids. A FEI Tecnai T12 twin transmission electron microscope was operated at $120 \mathrm{kV}$ for microscopic inspection of the ultrathin sections. A Gatan Orius dual-scan CCD was used for image acquisition.

SEM. A Zeiss LEO 1550 SEM with a field emission source was utilized to acquire images of calcined samples using an acceleration voltage of $2 \mathrm{kV}$ and an in-lens secondary electron detector. 


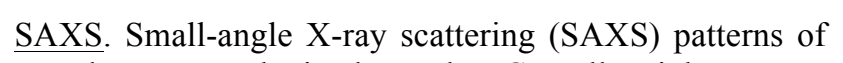
samples were obtained at the Cornell High Energy Synchrotron Source (CHESS) G1 station with a beam energy of $9 \mathrm{keV}$ as well as at a home-built Rigaku RU300 $\mathrm{Cu} \mathrm{K} \alpha$ rotating anode beamline. The details of both SAXS beamline configurations are described elsewhere. ${ }^{69}$ For acquiring time-resolved SAXS patterns at the CHESS G1 station, portions of films were transferred from Teflon dishes to $1.0 \mathrm{~mm}$ glass capillaries or on a Kapton tape immediately before the measurements. The degree of solvent evaporation at each time point was estimated by measuring the weight of the film in the dish. Acquired 2D patterns were radially integrated around the beam center to produce plots of intensity versus scattering vector magnitude, $q$, defined as $q=4 \pi \sin \theta / \lambda$, where $2 \theta$ is the total scattering angle and $\lambda$ is the $\mathrm{x}$-ray wavelength.

Physisorption. Nitrogen physisorption isotherms were measured at $-196{ }^{\circ} \mathrm{C}$ using a Micromeritics ASAP 2020 system. All samples were degassed under high vacuum at $150{ }^{\circ} \mathrm{C}$ overnight. The Brunauer, Emmett, and Teller (BET) and Brunauer, Jonyer, and Halenda (BJH) analyses were performed using the Micromeritics ASAP 2020 V1.05 software. ${ }^{76,77}$

XRD. Wide-angle X-ray diffraction measurements were performed using a Rigaku Ultima VI diffractometer at 40 $\mathrm{kV}$ and $44 \mathrm{~mA}$ where samples were scanned from 10 to 90 degrees with a 5 degrees/min speed.

\section{Results and Discussion}

\section{Solvent evaporation-induced structure formation}

The dissolution of an SDA and an inorganic material is the fundamental first step towards their evaporative coassembly. However, typical hydrolytic sol-gel protocols for the coassembly of ordered titania films start with $\sim 2$ $21 \mathrm{wt} \%$ SDA solutions of Pluronic ${ }^{39,54}$ or $\mathrm{KLE}^{33}$ in ethanol with $\sim 8-21 \mathrm{wt} \%$ water. Such alcohol and water rich solutions are incompatible with the dissolution of a tremendous diversity of other potential polymer systems, including most derivatives of acrylates, methacrylates, styrenes, or dienes. The solubility of a particular component may be predicted from the Hildebrand solubility parameter $(\delta)$ which for a given molecule is the square root of its cohesive energy density and is measured in SI units of $\sqrt{ }\left(\mathrm{Jm}^{-3}\right)$ or equivalently in $\sqrt{\mathrm{Pa}}$. Most $\delta$ values range from 14.9 to $47.9 \sqrt{\mathrm{MPa}}$, intermediate between hexanes and water, respectively (Figure 2). ${ }^{78}$ Ethanol with $\delta=26.6 \sqrt{ } \mathrm{MPa}$ is too hydrophilic to dissolve many common polymers such as polyisoprene, polystyrene, or poly(methyl methacrylate) $(\delta=16.5,18.6$, and $22.7 \sqrt{\mathrm{MPa}}$, respectively). However, the simple substitution of ethanol with common hydrophobic solvents such as hexane, toluene, or chloroform $(\delta=14.9$, 18.2 , and $19.0 \sqrt{\mathrm{MPa}}$ respectively) leads to the precipitation of the titania sol since these solvents do not hydrogen bond. The solubility parameter for acetylacetonate modified titania particles ${ }^{79}$ and bare rutile particles $^{80}$ are 20.5 and $30.1 \sqrt{\mathrm{MPa}}$, respectively. The dissolution of all species requires the selection of a solvent or a mixture of solvents with a similar $\delta$ value and an appropriate hydrogen bonding strength. Therefore solvents such as THF with a low $\delta=18.6 \sqrt{ } \mathrm{MPa}$ value and a moderate ability to hydrogen bond should be appropriate for many systems involving hydrophobic polymer blocks (Figure 2). Indeed, THF is a good solvent for many polymers including all of those mentioned above and for this reason is one of the most common eluent solvents for gel permeation chromatography of polymers. As a result, THF was chosen as the principal solvent for the coassembly of titania sols with the highly amphiphilic PI- $b$-PEO.

Dissolution of all coassembled species is required but not sufficient for the formation of equilibrated coassemblies. For example, the water associated with hydrolytic sol-gel processes may concentrate in the solution as volatile organic solvents often evaporate preferentially, leading to the precipitation of hydrophobic polymers. The measured precipitation point for $\mathrm{IO} 28 \mathrm{~K}$ is $\sim 4.1 \mathrm{wt} . \%$ water in THF determined using $\mathrm{HCl}(\mathrm{aq})$. Additionally, the composition of a mixed solvent system must remain favorable for all species present throughout the entire evaporation process. Relative evaporation rates and any azeotropic conditions should be considered for such mixed solvent systems. For example, mixtures of THF and water at atmospheric pressure form an azeotrope with a lowered boiling point of $64{ }^{\circ} \mathrm{C}$ and a composition of 5.3 wt.\% water. Note however that deviations from the azeotropic temperature or the addition of other reagents may change the relative evaporation rates. The recipe for sample IO28K-h4 was adapted from reported titania coassembly protocols with the simple substitution of THF in place of ethanol. Note that before the addition of titanium isopropoxide the solution was close to, but slightly below, the threshold for polymer precipitation ( $4 \%$ vs $4.1 \%$, respectively). Hydrolysis is expected to proceed quickly once the alkoxide is added, consuming all of the free water $\left(\mathrm{TiR}_{4}: \mathrm{H}_{2} \mathrm{O}=4.0: 1.0\right),{ }^{14}$ although some of this consumed water is expected to be released during the slow condensation reaction while stirring and casting. The initially orange color fading to clear overtime is consistent with initial THF coordination to the in-situ formed $\mathrm{Ti}\left(\mathrm{O}^{\mathrm{i}} \mathrm{Pr}\right)_{\mathrm{a}} \mathrm{Cl}_{\mathrm{b}}(\mathrm{OH})_{4-\mathrm{a}-\mathrm{b}}$ followed by reduction in coordination as the sol particles grow, lowering specific surface area. ${ }^{81}$

A titania:PI- $b$-PEO mass ratio of 2.0:1.0 was chosen to result in an inverse hexagonal $(\mathrm{iH})$ morphology based on the previously established morphology map for the coassembly of PI- $b$-PEO with an aluminosilicate sol. ${ }^{67}$ However, bright field TEM images of the resulting film show hollow dark circles consistent with an inverse spherical micelle (iSM) morphology containing PI cores (light) and $\mathrm{PEO}-\mathrm{TiO}_{2}$ coronas (dark) (Figure $1 \mathrm{~b}$ and c). Quantitative TEM image analysis indicated that these crew cut micelles had a diameter of $30 \pm 3 \mathrm{~nm}$, similar to the value obtained from the primary peak located at $\mathrm{q}^{*}=0.23 \mathrm{~nm}^{-1}$ in SAXS measurements (Figure 1a), corresponding to a spacing of $27 \mathrm{~nm}$. A broad second peak was also observed at approximately twice the reciprocal spacing of the first peak. These are too few peaks to make an unambiguous morphology assignment on the basis of SAXS alone. Hence, in this and other similar cases the morphology assignments were made on 
the basis of the greatest consistency between the SAXS and electron microscopy data. For example, the SAXS in Figure 1a was consistent with a simple cubic lattice, but not with either BCC nor FCC packing. However, longrange order was not apparent in the TEM observations, so the second SAXS peak was attributed to random packing of spheres. Extensive previous experiments indicate that the utilized $\mathrm{IO} 28 \mathrm{~K}$ should result in about $16 \mathrm{~nm}$ diameter $\mathrm{iH}$ cylinders. The larger than expected micelle diameters and deviation from the expected morphology suggest that sample IO28K-h4 was not equilibrated at the time of inorganic cross-linking, but was trapped in the solution morphology due to solvent selectivity of the PEO phase.

Solvent composition plays a key role as the polymer system transitions from solution dynamics to condensed matter behavior ("bulk"). ${ }^{82,83}$ If the solvent composition is favorable for all components, i.e., non-selective, then the block copolymer chains exist as non-aggregated unimers evenly distributed throughout the solution. Consequently, the hybrid would gradually enter bulk behavior from a random mixed state. In contrast, when the solvent composition favors one portion of an amphiphilic polymer, the solvophobic blocks aggregate leading to micelle formation, typically with a spherical morphology. Published examples indicate that the addition of 3-11 wt.\% of a selective solvent to a block copolymer solution in a non-selective solvent is sufficient to induce micellization, depending on the particular blocks, block lengths, and solvents involved. ${ }^{82,} 84-86$ Indeed, the $\mathrm{IO} 28 \mathrm{~K}$ used in this study was significantly longer $(28 \mathrm{~kg} / \mathrm{mol})$ and more hydrophobic (72 $\mathrm{wt} \% \mathrm{PI})$, than the block copolymers typically used for micellization studies. One may anticipate this polymer should be more sensitive to the presence of selective hydrophilic solvents, vide infra.

To elucidate the role of residual water during film casting, several nearly identical films were prepared, only varying the quantity of THF added. With increasing THF content, the starting weight fraction of water was lowered sequentially from IO28K-h4, IO28K-h3, IO28K-h2, to IO28K-h1. The iSM morphology of the sample with the least THF, IO28K-h4, was already described, vide supra. Before describing the intermediate samples, we focus on IO28K-h1, the sample with the most THF added, i.e. the lowest water concentration. The SAXS pattern for IO28K-h1 was consistent with an inverse hexagonally arranged cylinders (iH) morphology (Figure 1j), with the primary peak at $\mathrm{q}^{*}=0.20 \mathrm{~nm}^{-1}$. The allowed peaks for hexagonal symmetry are indicated in the figure at $\left(\mathrm{q} / \mathrm{q}^{*}\right)^{2}=1,3,4,7,9$ and 11. Additionally, significant sample texturing was evidenced by a pair of spots for $\left(q / q^{*}\right)^{2}=4$ peaks (data not shown). TEM observations confirmed the presence of an iH morphology having PI cylinders (light) hexagonally arranged within a $\mathrm{PEO}-\mathrm{TiO}_{2}$ matrix (dark) (Figure $1 \mathrm{k}$ and $\mathrm{j}$ ). Quantitative TEM measurements indicated a cylinder-to-cylinder spacing of $30 \pm 2 \mathrm{~nm}$, compared to the SAXS indicating $36.4 \mathrm{~nm}$. The cylinder diameter and titania wall thickness as determined from TEM measurements were $16 \pm 2 \mathrm{~nm}$ and $14 \pm 1 \mathrm{~nm}$, respectively. Such a large hexagonal structure with thick walls is expected to be thermally more stable than the smaller dimensions typically obtained from Pluronic or KLE polymers (Table I).

The intermediate samples exhibited mixed morphologies between the two boundary cases of IO28K-h4 and IO28K-h1. The SAXS pattern of sample IO28K-h3 was similar to that of IO28K-h4, but with the addition of a shoulder consistent with the $\mathrm{q}^{*}$ peak of IO28K-h1 (Figure 1d). TEM images of sample IO28K-h3 contained primarily $\sim 30 \mathrm{~nm}$ inverse spherical micelles, similar to sample IO28K-h4, but with added minority domains with $\mathrm{iH}$ morphology (Figure 1e and f). The SAXS pattern of IO28K-h2 was similar to the bimodal pattern of IO28K$\mathrm{h} 3$, but the intensity distribution in the convoluted first peak indicated a decreased content of iSM and an increased content of $\mathrm{iH}$ (Figure $1 \mathrm{~g}$ ). This trend was confirmed by TEM imaging which revealed primarily domains with iH morphology with a minority of $\sim 30 \mathrm{~nm}$ iSMs (Figure $1 \mathrm{~h}$ and $\mathrm{f}$ ). The structural analysis of this series of samples indicates a strong morphological dependence on solution conditions during evaporation.

The predominant mechanisms of micelle equilibration, unimer expulsion-insertion and micelle fusion-fission, are dependent upon the interaction strength between the solvophobic block and the solvent. ${ }^{87}$ Although there is still discussion concerning the interplay of these mechanisms, ${ }^{87-89}$ the equilibration rates and affecting factors were nonetheless measurable. The exchange kinetics for block copolymer micelles generally range from slow, i.e. 1-100 billion times slower than small molecule surfactants, ${ }^{90}$ to immeasurably slow. ${ }^{91-96}$ The unimer exchange rate was found to depend exponentially on the surface tension penalty for solvophobe-solvent contact. $^{97,98}$ Lodge et al. recently found that unimer exchange was hypersensitive to the length of the solvophobic chains with a double exponential dependence enabling the precise measurement of polydispersity from the ensemble. ${ }^{99}$ For the present study, the differences in morphological behavior could be attributed to the different starting points for solvent compositions before evaporation (Figure 2b). All samples are expected to increase in water composition during evaporation with the particular starting water composition establishing a trajectory to the final water composition. Therefore, the evolution dynamics and morphology should depend on the selectivity of the solvent mixture during coassembly. The enthalpy associated with solvophobic contacts may be crudely estimated using:

$$
\chi_{12} \approx \frac{v}{k_{b} T}\left(\delta_{1}-\delta_{2}\right)^{2}
$$

Here the Flory-Huggins $\chi_{12}$ parameter for enthalpic $1-2$ type contacts scales with the square of the difference of the respective Hildebrand solubility parameters $(\delta)$ for components 1 (polyisoprene) and 2 (solvent mixture), as well as the average molecular volume (v), Boltzmann's constant $\left(\mathrm{k}_{\mathrm{b}}\right)$, and temperature $(\mathrm{T})$. For PI- $b$-PEO in $\mathrm{THF} /$ water mixtures, the solutions with higher water content will have higher solubility parameters and thus produce more enthalpic contacts with the solvophobic poly(isoprene) block, inhibiting structural transitions. This rational is consistent with the behavior observed in Figure 1 where water-rich mixtures prevented the 
transition from micellar solutions to solid-state equilibrium morphologies. Our rational design strategy for equilibrated morphologies thus requires a low degree of solvophobic interactions at the transition to the solidstate. The solubility parameter for each of the starting mixtures is presented in Figure $2 b$. It is straight forward to use equation 1 to estimate the Flory-Huggins parameter for poly(isoprene) with each of the starting solvent mixtures. However, the crucial composition at the transition from solution to the solid-state is difficult to predict a priori due to synergistic evaporative effects such as the formation of positive or negative azeotropes with multi-component systems. The difficulty in predicting solvent composition during evaporation thus makes our design guidelines semi-quantitative.

To further elucidate the structural changes during casting, in-situ SAXS measurements were performed. Sample IO28K-h1 did not exhibit any scattering patterns in solution until a broad hump appeared 80 minutes after casting (10\% retained mass) just prior to becoming a semisolid and then proceeded directly to the iH scattering pattern at the next measurement at 86 minutes (Figure $\mathrm{S} 1)$. Although the temporal resolution was insufficient to elucidate the molecular dynamics, the measurements did indicate that the key period for structure formation is the last minutes of casting as the semisolid films formed.

Considering these findings it is surprising that ordered aluminosilicate morphologies were ever achieved with PI$b$-PEOs. Typical recipes for such hybrids start with a 5 wt.\% polymer solution and utilize an inorganic:organic ratio of 2 , leading to $12.7 \mathrm{wt} . \%$ water before hydrolysis and 2.3 wt.\% water after complete hydrolysis. The apparent insensitivity to water could be due to at least two factors: 1) Silicate sols undergo condensation much slower than transition metal oxides which would result in less water release after hydrolysis. 2) Silicate gels formed under acidic conditions tend to exhibit fractal networks with high internal surface areas. ${ }^{14}$ Such a porous gel might physisorb much of the free-water from solution, preventing PI- $b$-PEO micellization. Furthermore, these results elucidate the morphological behavior of KLE structure-directing agents, which regardless of inorganic:organic ratio seem to always form spherical micellar morphologies. It is likely that the use of water and alcohol rich solutions to prepare these hybrids leads to trapping the KLE in a selective solvent-induced morphology and preventing the evolution of other morphologies.

\section{Mesoporous materials}

The conversion of sample IO28K-h1 to mesoporous crystalline titania was tested employing the CASH procedure described previously in detail. ${ }^{66}$ The first calcination of IO28K-h1 was carried out at $700{ }^{\circ} \mathrm{C}$ under $\mathrm{N}_{2}$, leading to sample IO28K-h1-C. The resulting material was black, consistent with the expected carbon residue. SEM images of IO28K-h1-C indicated that the highly ordered $\mathrm{iH}$ morphology of IO28K-h1 survived the high temperature treatment (Figure S2a). Quantitative measurements from the SEM images indicated an average cylinder-to-cylinder distance of $26.8 \pm 3.7 \mathrm{~nm}$ with a cylinder diameter of $12.4 \pm 2.7 \mathrm{~nm}$ and a wall thickness of $12.8 \pm 2.0 \mathrm{~nm}$. SAXS measurements similarly confirmed $25.7 \%$ shrinkage with a similar cylinder-to-cylinder distance of $27.0 \mathrm{~nm}$ (Figure S2c). Many coassembled oxide structures have mesostructural compression along the film normal. ${ }^{28,} 69,71,72,100,101$ This compression complicates SAXS analysis since the orientation of the powdered sample was unknown and thus the longest realspace $d_{10}$ dimension from the elliptical scattering pattern was assumed to coincide with the film normal and was thus used for comparison. Wide angle XRD analysis of IO28K-h1-C confirmed the presence of anatase titania (PDF\#21-1272) with a Scherrer average domain size of $9.7 \mathrm{~nm}$ calculated from the non-convoluted (101) and (200) peaks (Figure S2e). Although the diffraction pattern was dominantly anatase, there was a trace quantity of rutile (PDF\#1088-1172). Previous CASH studies on related materials demonstrated a larger extent of rutile with heat treatments as high as $1,000{ }^{\circ} \mathrm{C} .{ }^{66}$ Nitrogen physisorption of IO28K-h1-C exhibited a classic type IV isotherm with an $\mathrm{H}_{2}$ hysteresis loop ${ }^{18}$ (Figure $\mathrm{S} 2 \mathrm{~h}$ ) indicative of mesopores with restricted pathways (ink bottle). A heterogeneous carbon distribution throughout the cylindrical pores could be the cause of this hysteresis loop. The application of the BET model led to a calculated overall surface area of $124.7 \mathrm{~m}^{2} / \mathrm{g}$. BJH analysis of the adsorption branch led to an average mesopore size of $12.5 \mathrm{~nm}$ (Figure S2i). The carbon was removed from IO28K-h1-C by heating to $450{ }^{\circ} \mathrm{C}$ in air resulting in IO28K-h1-CASH. The white product was consistent with oxidative removal of the carbon. SEM imaging of IO28K-h1-CASH indicated that the ordered $\mathrm{iH}$ mesostructure survived removal of the carbon (Figure $\mathrm{S} 2 \mathrm{~b})$. The analysis of the SEM images indicated a cylinder diameter of $12.7 \pm 1.8 \mathrm{~nm}$, a wall thickness of $10.2 \pm 1.7 \mathrm{~nm}$, and a cylinder-to-cylinder distance $25.5 \pm$ $3.0 \mathrm{~nm}$. This compares to a cylinder-to-cylinder distance of $25.7 \mathrm{~nm}$ as determined by SAXS measurements. The SAXS pattern again contained a broad first-order peak suggesting the preservation of the mesostructure, although higher ordered peaks were no longer detected (Figure S2d). Again, wide angle XRD confirmed the presence of anatase titania with a Scherrer average domain size of $10.8 \mathrm{~nm}$ and again a trace of rutile. Physisorption analysis of IO28K-h1-CASH exhibited a classical type IV isotherm with a very small hysteresis, consistent with long cylindrical pores of homogeneous diameter (Figure $\mathrm{S} 2 \mathrm{~h}$ ). The absence of an $\mathrm{H}_{2}$ hysteresis loop for sample IO28K-h1-CASH indicates that the carbon residue of IO28K-h1-C was partially blocking the mesopores. The application of the BJH model to the adsorption isotherm led to an average mesopore size of $16.1 \mathrm{~nm}$ consistent with an additional densification of the titania after carbon removal (Figure S2i). The BET analysis was also consistent with this densification indicating a reduced overall surface area of $82.4 \mathrm{~m}^{2} / \mathrm{g}$. This data set indicates that the CASH method was successfully applied to the materials described herein.

The previous examples demonstrate that these solubility design principles can guide the formation of ordered mesoporous transition metal oxide structures from highly amphiphilic block copolymers. Exploiting different 
molecular weight PI- $b$-PEOs together with the solubility design guidelines and the CASH method described above enabled unprecedented pore size control in mesoporous crystalline titania. To this end, inverse hexagonal $\mathrm{TiO}_{2}-\mathrm{IO}$ hybrid materials were prepared with the same inorganicorganic ratio using different molar mass PI- $b$-PEOs, ranging from 92 to $7 \mathrm{~kg} / \mathrm{mol}$. Indeed, bright field TEM images and SAXS measurements of all hybrids were consistent with highly ordered $\mathrm{iH}$ morphologies (Figure 3). The SAXS spectra show higher order peaks at $\left(\mathrm{q} / \mathrm{q}^{*}\right)^{2}=4$ and 7 for all hybrid materials while the cylinder-to-cylinder distances decreased from 72.7 to 15.9 $\mathrm{nm}$, consistent with the decrease of the PI- $b$-PEO molar mass.

Highly ordered mesoporous and crystalline titania was synthesized from these hybrids via the CASH method. The hybrids were heated to $700{ }^{\circ} \mathrm{C}$ and dwelled for $4 \mathrm{hrs}$ in nitrogen with subsequent calcination at $450{ }^{\circ} \mathrm{C}$ in air to yield crystalline titania as confirmed by wide angle XRD analysis. XRD spectra indicate mostly the anatase phase with a trace amount of rutile for IO92K-CASH, IO41KCASH and IO13K-CASH samples (Figure S4). A purely anatase crystalline phase was achieved by adjusting the temperature and time of the first heat treatment step of the CASH method, as confirmed by the XRD spectra for IO92K-CASH (Figure 4c), IO41K-CASH, IO13K-CASH and IO7K-CASH (Figure S5). Details of the respective heat processing conditions are described in Table S1 showing that block copolymer directed titania can be transformed into highly crystalline and phase-pure anatase upon heat treatments at $600-700{ }^{\circ} \mathrm{C}$ for $2-4 \mathrm{hrs}$.

The characterization of the largest pore size titania with a highly ordered and crystalline structure is presented in Figure 4. The SEM images verified the presence of a highly ordered hexagonally arranged cylindrical morphology of the anatase titania after removal of the block copolymer template (Figure 4a), consistent with TEM results (Figure S3). TEM analysis was performed after the brittle titania samples were ground and put on carbon-coated grids. The crushed particles were neither uniform in thickness nor ultrathin and only the edges could be imaged. The highly ordered mesostructure was further confirmed by SAXS analysis showing higher order peaks at $\left(\mathrm{q} / \mathrm{q}^{*}\right)^{2}=1,4$ and 7 as in the IO92K-h hybrid material (Figure 4b). The SAXS cylinder-tocylinder spacing was determined to be $56.0 \mathrm{~nm}$, indicating a $23 \%$ shrinkage upon removal of the block copolymer template from the hybrid material and crystallization of titania (compared to original $72.7 \mathrm{~nm}$ ) via the CASH method. Nitrogen physisorption measurements revealed a narrow pore size distribution with an average pore size of $32.3 \mathrm{~nm}$ along with a classical type IV isotherm that is typical of mesoporous materials with a cylindrical pore geometry and a highly uniform pore size distribution (Figure 4e). The anatase crystallite domain size was calculated to be $11.9 \mathrm{~nm}$ using the Scherrer equation.

The structural characteristics of block copolymer derived titania hybrids and the resulting mesoporous crystalline titania with pore size control are summarized in Table III.
The surface areas obtained from BET analysis of nitrogen adsorption-desorption data are high, i.e. $64-85 \mathrm{~m}^{2} / \mathrm{g}$ for all mesoporous titania. The narrow pore size distributions and the type IV isotherms of titania for IO41K-CASH, IO13K-CASH and IO7K-CASH are consistent with the results described for IO92K-CASH (Figure S6). Figure 5 displays the dependence of SAXS derived d-spacings and BJH derived pore sizes on the PI- $b$-PEO molar mass for the various titania/PI- $b$-PEO hybrids and the resulting mesoporous crystalline titania materials $\left(\mathrm{R}^{2}>0.99\right)$ investigated. To the best of our knowledge, ${ }^{102}$ we report here the largest pore size to date $(32.3 \mathrm{~nm})$ for highly ordered crystalline titania from a block copolymerinorganic coassembly approach without the use of pore expanding agents.

The solubility design criteria are also generalizable to more complex ABC triblock terpolymers. Poly(isoprene$b$-styrene- $b$-ethylene oxide) (ISO) was selected since it contains two common hydrophobic blocks, i.e., polyisoprene and polystyrene, and has recently been used for the production of $3 \mathrm{D}$ networked aluminosilicate and niobia morphologies with a wide composition window. ${ }^{72}$, ${ }^{75}$ Such networked morphologies have unique advantages in that they have three-dimensional continuity of all three phases and can maintain percolation pathways with lower than 30 vol. $\%$ of oxide. Casting solutions were prepared with very low $\sim 1$ wt. $\%$ water content to enhance the solubility of the hydrophobic blocks during casting (Figure 2c). The successful production of ordered network morphologies from ISO1 combined with titania sols is demonstrated by sample ISO1- $\mathrm{TiO}_{2}$. Microtomed sections of this sample clearly show an ordered network connectivity (Figure 6a,b) with both four-fold and threefold symmetry, consistent with a cubic network morphology. The SAXS pattern for ISO1-TiO2 contained two broad peaks that were rather equivocal to interpret directly (Figure 6c). However, previous experiments with the same ISO1 polymer and niobia sols exhibited a similar scattering pattern and was determined by electron tomography to be consistent with an $\mathrm{O}^{70}$ morphology with an equilateral unit cell. Quantitative TEM measurements from these projections yielded a $d_{100}$ spacing of $37-48$ $\mathrm{nm}$ compared to $\mathrm{d}_{100}=57.0 \mathrm{~nm}$ determined by interpreting the first SAXS peak as $d_{110}$. Such smaller than expected TEM measurement values have been observed before for similar samples containing low $T_{g}$ blocks that can reflow after microtoming causing structural distortions. ${ }^{22,72,75}$ This discrepancy is notably absent for the comparison of SAXS and electron microscopy data for calcined samples that do not contain polyisoprene, vide infra. The titania nanostructures from the coassembly with ISO1 demonstrate that the solubility design guidelines enable the use of complex triblock terpolymers to synthesize highly ordered nanocomposites with novel morphologies.

The crystallization of the $\mathrm{ISO} 1-\mathrm{TiO}_{2}$ network was studied with a combination of electron microscopy, SAXS, and XRD. Initial experiments calcining ISO1- $\mathrm{TiO}_{2}$ indicated that this mesostructure with a minority of oxide is not able to survive high temperature heat treatments. For example, bulk films exhibited significant collapse after 
heating to $450{ }^{\circ} \mathrm{C}$. We therefore compare heat treatments at $400{ }^{\circ} \mathrm{C}$ in $\mathrm{N}_{2}$ or air, resulting in the samples ISO1$\mathrm{TiO}_{2}-\mathrm{N}_{2}$ and ISO1-TiO -air, respectively. The mesostructure of both samples survived the heat treatment as evidenced by both SEM images and SAXS observations (Figure $7 \mathrm{a}-\mathrm{d}$ ). The $\mathrm{d}_{100}$ spacing of sample ISO1- $-\mathrm{TiO}_{2}-\mathrm{N}_{2}$ was determined from SAXS and SEM as $45.0 \mathrm{~nm}$ and $42.6 \pm 4.4 \mathrm{~nm}$, respectively. Sample ISO1$\mathrm{TiO}_{2}$-air also had a smaller $\mathrm{d}_{100}$ spacing which was measured by SAXS and SEM as $39.5 \mathrm{~nm}$ and $40.7 \pm 3.0$ $\mathrm{nm}$, respectively. The comparison of the SAXS $\mathrm{d}_{100}$ spacings indicates that $\mathrm{ISO} 1-\mathrm{TiO}_{2}-\mathrm{N}_{2}$ experienced a contraction of $21 \%$, less than the $31 \%$ observed for ISO1$\mathrm{TiO}_{2}$-air. This is likely due to the in-situ formation of a carbonaceous hard template as in the CASH procedure. XRD spectra of both samples were consistent with nanocrystallites of anatase titania (Figure 5e-g). The low intensity of anatase peaks in sample ISO1- $\mathrm{TiO}_{2}-\mathrm{N}_{2}$ suggests the presence of a significant amount of amorphous titania. Comparison of the ISO1- $\mathrm{TiO}_{2}-\mathrm{N}_{2}$ and ISO1- $\mathrm{TiO}_{2}$-air suggest that the in-situ formed carbonaceous material constrains the crystallization process by providing a diffusion barrier. Scherrer analysis of the non-convoluted (101) and (200) peaks of ISO1$\mathrm{TiO}_{2}$-air indicated an average crystallite size of $7.5 \mathrm{~nm}$. These results suggest that when constrained to lower temperature heat treatments, calcination in air yields more crystalline anatase. ${ }^{103}$ We anticipate that such ordered mesoporous networks of crystalline titania will enable better a performance of next generation energy materials.

\section{Conclusions}

Solubility design guidelines were established for the development of novel coassembly systems using block copolymer structure-directing agents. This strategy addresses the general challenge of multi-component coassembly with a range of intermolecular interaction strengths. We demonstrated that the evaporation conditions during coassembly play a decisive role in the formation of ordered structures. In the presented examples, the accumulation a water in the solution can trap the assembly in a micellar morphology, preventing the realization of equilibrium block copolymer morphologies. These solubility challenges are exacerbated by the development of more complex and higher molecular weight block copolymers. Our semiquantitative strategy relying on solubility parameters has enabled the manufacture of mesoporous titania with ultralarge pores using a high molecular weight IO diblock copolymer as well as a novel titania network morphology by using an ISO triblock terpolymer. In all cases, subsequent calcination treatments enabled the formation of highly crystalline mesoporous materials while preserving the mesostructure.

Supporting Information: In-situ SAXS data, additional SEM, TEM, XRD, SAXS, and physisorption data, as well as a table summary of calcination conditions.

\section{Acknowledgments}

This work was supported by the National Science Foundation Single Investigator Award (DMR-1409105). MS acknowledges the University of South Carolina for startup funds. JS was supported by GS Caltex Corporation in South Korea. SG is grateful for support by KUSC1018-02, awarded by King Abdullah University of Science and Technology (KAUST) and the German Academy of Sciences (Leopoldina), Fellowship LPDS2012-13. This work made use of the Cornell Center for Materials Research Shared Facilities, supported through the NSF Materials Research Science and Engineering Centers program (grant DMR 1120296). Some X-ray equipment was supported by Department of Energy grant DE-FG0211ER16210. CHESS is supported by the NSF and NIHNIGMS via DMR-1332208. 
(1) M. Zukalova, A. Zukal, L. Kavan, M. K. Nazeeruddin, P. Liska, M. Gratzel, Organized mesoporous TiO2 films exhibiting greatly enhanced performance in dye-sensitized solar cells, Nano Letters, 2005, 5, 1789-1792.

(2) M. Nedelcu, J. Lee, E. J. W. Crossland, S. C. Warren, M. C. Orilall, S. Guldin, S. Huttner, C. Ducati, D. Eder, U. Wiesner, U. Steiner, H. J. Snaith, Block copolymer directed synthesis of mesoporous TiO2 for dye-sensitized solar cells, Soft Matter, 2009, 5, 134-139.

(3) J. M. Szeifert, D. Fattakhova-Rohlfing, D. Georgiadou, V. Kalousek, J. Rathousky, D. Kuang, S. Wenger, S. M. Zakeeruddin, M. Gratzel, T. Bein, "Brick and Mortar" Strategy for the Formation of Highly Crystalline Mesoporous Titania Films from Nanocrystalline Building Blocks, Chemistry of Materials, 2009, 21, $1260-1265$.

(4) P. Docampo, S. Guldin, M. Stefik, P. Tiwana, M. C. Orilall, S. Huttner, H. Sai, U. Wiesner, U. Steiner, H. J. Snaith, Control of Solid-State Dye-Sensitized Solar Cell Performance by Block-Copolymer-Directed TiO2 Synthesis, Advanced Functional Materials, 2010, 20, 1787-1796.

(5) S. Guldin, S. Huttner, M. Kolle, M. E. Welland, P. Muller-Buschbaum, R. H. Friend, U. Steiner, N. Tetreault, Dye-Sensitized Solar Cell Based on a Three-Dimensional Photonic Crystal, Nano Letters, 2010, 10, $2303-2309$.

(6) L. Li, M. Krissanasaeranee, S. W. Pattinson, M. Stefik, U. Wiesner, U. Steiner, D. Eder, Enhanced photocatalytic properties in well-ordered mesoporous WO(3), Chemical Communications, 2010, 46, 7620-7622.

(7) B. O’Regan, M. Grätzel, A low-cost, high-efficiency solar cell based on dye-sensitized colloidal TiO2 films, Nature, 1991, 353, 737-740.

(8) G. Sudant, E. Baudrin, D. Larcher, J.-M. Tarascon, Electrochemical lithium reactivity with nanotextured anatasetype TiO2, Journal of Materials Chemistry, 2005,

(9) Y. Wang, J. Tang, Z. Peng, Y. Wang, D. Jia, B. Kong, A. A. Elzatahry, D. Zhao, G. Zheng, Fully solar-powered photoelectrochemical conversion for simultaneous energy storage and chemical sensing., Nano Letters, 2014, 14, 3668-3673.

(10) W. Li, Z. Wu, J. Wang, A. A. Elzatahry, D. Zhao, A Perspective on Mesoporous TiO Materials, Chemistry of Materials, 2014, 26, 287-298.

(11) M. C. Orilall, U. Wiesner, Block copolymer based composition and morphology control in nanostructured hybrid materials for energy conversion and storage: solar cells, batteries, and fuel cells., Chemical Society Reviews, 2011, 40, 520-535.

(12) T. Yanagisawa, T. Shimizu, K. Kuroda, C. Kato, The preparation of alkyltrimethylammonium-kanemite complexes and their conversion to microporous materials, Bulletin of the Chemical Society of Japan, 1990, 63, 988-992.

(13) C. T. Kresge, M. E. Leonowicz, W. J. Roth, J. C. Vartuli, J. S. Beck, Ordered Mesoporous Molecular-Sieves Synthesized by a Liquid-Crystal Template Mechanism, Nature, 1992, 359, 710-712.

(14) BrinkerC. J., SchererG. W. Sol-gel science : the physics and chemistry of sol-gel processing; Academic Press: Boston, 1990;

(15) Q. S. Huo, D. I. Margolese, U. Ciesla, P. Y. Feng, T. E. Gier, P. Sieger, R. Leon, P. M. Petroff, F. Schuth, G. D. Stucky, Generalized Synthesis of Periodic Surfactant Inorganic Composite-materials, Nature, 1994, 368, 317 321.

(16) D. M. Antonelli, J. Y. Ying, Synthesis of Hexagonally Packed Mesoporous $\mathrm{TiO}_{2}$ by a Modified Sol-Gel Method, Angewandte Chemie-International Edition in English, 1995, 34, 2014-2017.

(17) J. Rouquerol, D. Avnir, C. W. Fairbridge, D. H. Everett, J. H. Haynes, N. Pernicone, J. D. F. Ramsay, K. S. W. Sing, K. K. Unger, Recommendations for the Characterization of Porous Solids, Pure and Applied Chemistry, 1994, 66, 1739-1758.

(18) K. S. W. Sing, D. H. Everett, R. A. W. Haul, L. Moscou, R. A. Pierotti, J. Rouquerol, T. Siemieniewska, Reporting Physisorption Data for Gas Solid Systems with Special Reference to the Determination of SurfaceArea and Porosity, Pure and Applied Chemistry, 1985, 57, 603-619.

(19) N. K. Raman, M. T. Anderson, C. J. Brinker, Template-based approaches to the preparation of amorphous, nanoporous silicas, Chemistry of Materials, 1996, 8 , 1682-1701.

(20) S. A. Bagshaw, E. Prouzet, T. J. Pinnavaia, Templating of Mesoporous Molecular-Sieves by Nonionic Polyethylene Oxide Surfactants, Science, 1995, 269, 1242-1244.

(21) P. T. Tanev, T. J. Pinnavaia, A Neutral Templating Route to Mesoporous Molecular Sieves, Science, 1995, 267, 865-867.

(22) M. Templin, A. Franck, A. DuChesne, H. Leist, Y. M. Zhang, R. Ulrich, V. Schadler, U. Wiesner, Organically modified aluminosilicate mesostructures from block copolymer phases, Science, 1997, 278, 1795-1798.

(23) D. Y. Zhao, J. L. Feng, Q. S. Huo, N. Melosh, G. H. Fredrickson, B. F. Chmelka, G. D. Stucky, Triblock copolymer syntheses of mesoporous silica with periodic 50 to 300 angstrom pores, Science, 1998, 279, 548-552.

(24) P. D. Yang, D. Y. Zhao, D. I. Margolese, B. F. Chmelka, G. D. Stucky, Generalized syntheses of large-pore mesoporous metal oxides with semicrystalline frameworks, Nature, 1998, 396, 152-155.

(25) G. Wanka, H. Hoffmann, W. Ulbricht, Phase-Diagrams and Aggregation Behavior of Poly(oxyethylene)Poly(oxypropylene)-Poly(oxyethylene) Triblock Copolymers in Aqueous-Solutions, Macromolecules, 1994, 27, 4145-4159.

(26) P. D. Yang, D. Y. Zhao, D. I. Margolese, B. F. Chmelka, G. D. Stucky, Block copolymer templating syntheses of mesoporous metal oxides with large ordering lengths and semicrystalline framework, Chemistry of Materials, 
1999, 11, 2813-2826.

(27) L. Malfatti, M. G. Bellino, P. Innocenzi, G. Soler-Illia, One-Pot Route to Produce Hierarchically Porous Titania Thin Films by Controlled Self-Assembly, Swelling, and Phase Separation, Chemistry of Materials, 2009, 21, 2763-2769.

(28) E. L. Crepaldi, G. Soler-Illia, D. Grosso, F. Cagnol, F. Ribot, C. Sanchez, Controlled formation of highly organized mesoporous titania thin films: From mesostructured hybrids to mesoporous nanoanatase TiO2, Journal of the American Chemical Society, 2003, 125, 9770-9786.

(29) D. Grosso, G. Soler-Illia, E. L. Crepaldi, F. Cagnol, C. Sinturel, A. Bourgeois, A. Brunet-Bruneau, H. Amenitsch, P. A. Albouy, C. Sanchez, Highly porous TiO2 anatase optical thin films with cubic mesostructure stabilized at 700 degrees C, Chemistry of Materials, 2003, 15, 4562-4570.

(30) S. Y. Choi, M. Mamak, N. Coombs, N. Chopra, G. A. Ozin, Thermally stable two-dimensional hexagonal mesoporous nanocrystalline anatase, meso-nc-TiO2: Bulk and crack-free thin film morphologies, Advanced Functional Materials, 2004, 14, 335-344.

(31) B. Smarsly, D. Grosso, T. Brezesinski, N. Pinna, C. Boissiere, M. Antonietti, C. Sanchez, Highly crystalline cubic mesoporous $\mathrm{TiO} 2$ with 10-nm pore diameter made with a new block copolymer template, Chemistry of Materials, 2004, 16, 2948-2952.

(32) D. Fattakhova-Rohlfing, M. Wark, T. Brezesinski, B. M. Smarsly, J. Rathousky, Highly organized mesoporous TiO2 films with controlled crystallinity: A Li-insertion study, Advanced Functional Materials, 2007, 17, 123 132.

(33) T. Brezesinski, J. Wang, J. Polleux, B. Dunn, S. H. Tolbert, Templated Nanocrystal-Based Porous TiO2 Films for Next-Generation Electrochemical Capacitors, Journal of the American Chemical Society, 2009, 131, $1802-$ 1809.

(34) D. M. Antonelli, Synthesis of phosphorus-free mesoporous titania via templating with amine surfactants, Microporous and Mesoporous Materials, 1999, 30, 315-319.

(35) D. Khushalani, O. Dag, G. A. Ozin, A. Kuperman, Glycometallate-surfactants Part 2: non-aqueous synthesis of mesoporous titanium, zirconium and niobium oxides, Journal of Materials Chemistry, 1999, 9, 1491-1500.

(36) G. Soler-Illia, C. Sanchez, Interactions between poly(ethylene oxide)-based surfactants and transition metal alkoxides: their role in the templated construction of mesostructured hybrid organic-inorganic composites, New Journal of Chemistry, 2000, 24, 493-499.

(37) D. Grosso, G. Soler-Illia, F. Babonneau, C. Sanchez, P. A. Albouy, A. Brunet-Bruneau, A. R. Balkenende, Highly organized mesoporous titania thin films showing mono-oriented 2D hexagonal channels, Advanced Materials, 2001, 13, 1085-108+.

(38) G. Soler-Illia, E. Scolan, A. Louis, P. A. Albouy, C. Sanchez, Design of meso-structured titanium oxo based hybrid organic-inorganic networks, New Journal of Chemistry, 2001, 25, 156-165.

(39) P. C. A. Alberius, K. L. Frindell, R. C. Hayward, E. J. Kramer, G. D. Stucky, B. F. Chmelka, General predictive syntheses of cubic, hexagonal, and lamellar silica and titania mesostructured thin films, Chemistry of Materials, 2002, 14, 3284-3294.

(40) G. Soler-Illia, A. Louis, C. Sanchez, Synthesis and characterization of mesostructured titania-based materials through evaporation-induced self-assembly, Chemistry of Materials, 2002, 14, 750-759.

(41) N. Steunou, S. Forster, P. Florian, C. Sanchez, M. Antonietti, Synthesis of nanostructured polymer-titanium oxide composites through the assembly of titanium-oxo clusters and amphiphilic block copolymers micelles, Journal of Materials Chemistry, 2002, 12, 3426-3430.

(42) E. L. Crepaldi, G. Soler-Illia, D. Grosso, M. Sanchez, Nanocrystallised titania and zirconia mesoporous thin films exhibiting enhanced thermal stability, New Journal of Chemistry, 2003, 27, 9-13.

(43) O. Dag, I. Soten, O. Celik, S. Polarz, N. Coombs, G. A. Ozin, Solventless acid-free synthesis of mesostructured titania: Nanovessels for metal complexes and metal nanoclusters, Advanced Functional Materials, 2003, 13, 3036.

(44) P. C. Angelome, S. Aldabe-Bilmes, M. E. Calvo, E. L. Crepaldi, D. Grosso, C. Sanchez, G. Soler-Illia, Hybrid non-silica mesoporous thin films, New Journal of Chemistry, 2005, 29, 59-63.

(45) M. H. Bartl, S. W. Boettcher, K. L. Frindell, G. D. Stucky, 3-D molecular assembly of function in titania-based composite material systems, Accounts of Chemical Research, 2005, 38, 263-271.

(46) S. W. Boettcher, M. H. Bartl, J. G. Hu, G. D. Stucky, Structural analysis of hybrid titania-based mesostructured composites, Journal of the American Chemical Society, 2005, 127, 9721-9730.

(47) S. Y. Choi, M. Mamak, S. Speakman, N. Chopra, G. A. Ozin, Evolution of nanocrystallinity in periodic mesoporous anatase thin films, Small, 2005, 1, 226-232.

(48) M. Groenewolt, T. Brezesinski, H. Schlaad, M. Antonietti, P. W. Groh, B. Ivan, Polyisobutylene-blockpoly(ethylene oxide) for robust templating of highly ordered mesoporous materials, Advanced Materials, 2005, $17,1158-115+$.

(49) H. Shibata, T. Ogura, T. Mukai, T. Ohkubo, H. Sakai, M. Abe, Direct synthesis of mesoporous titania particles having a crystalline wall, Journal of the American Chemical Society, 2005, 127, 16396-16397.

(50) J. Fan, S. W. Boettcher, G. D. Stucky, Nanoparticle assembly of ordered multicomponent mesostructured metal oxides via a versatile sol-gel process, Chemistry of Materials, 2006, 18, 6391-6396.

(51) M. C. Fuertes, G. Soler-Illia, Processing of macroporous titania thin films: From multiscale functional porosity to 
nanocrystalline macroporous TiO2, Chemistry of Materials, 2006, 18, 2109-2117.

(52) Y. Sakatani, D. Grosso, L. Nicole, C. Boissiere, G. Soler-Illia, C. Sanchez, Optimised photocatalytic activity of grid-like mesoporous $\mathrm{TiO} 2$ films: effect of crystallinity, pore size distribution, and pore accessibility, Journal of Materials Chemistry, 2006, 16, 77-82.

(53) S. W. Boettcher, J. Fan, C. K. Tsung, Q. H. Shi, G. D. Stucky, Harnessing the sol-gel process for the assembly of non-silicate mesostructured oxide materials, Accounts of Chemical Research, 2007, 40, 784-792.

(54) W. Y. Dong, Y. J. Sun, C. W. Lee, W. M. Hua, X. C. Lu, Y. F. Shi, S. C. Zhang, J. M. Chen, D. Y. Zhao, Controllable and repeatable synthesis of thermally stable anatase nanocrystal-silica composites with highly ordered hexagonal mesostructures, Journal of the American Chemical Society, 2007, 129, 13894-13904.

(55) O. H. Park, J. Y. Cheng, H. S. Kim, P. M. Rice, T. Topuria, R. D. Miller, H. C. Kim, Formation and photopatterning of nanoporous titania thin films, Applied Physics Letters, 2007, 90, 3.

(56) J. D. Bass, D. Grosso, C. Boissiere, C. Sanchez, Pyrolysis, crystallization, and sintering of mesostructured titania thin films assessed by in situ thermal ellipsometry, Journal of the American Chemical Society, 2008, 130, 78827897.

(57) S. Sokolov, E. Ortel, R. Kraehnert, Mesoporous titania films with adjustable pore size coated on stainless steel substrates, Materials Research Bulletin, 2009, 44, 2222-2227.

(58) K. J. Edler, A. M. Hawley, B. M. D. O’Driscoll, R. Schweins, Association of Titania with Nonionic Block Copolymers in Ethanol: The Early Stages of Templating and Film Formation, Chemistry of Materials, 2010, 22, 4579-4590.

(59) Y. Deng, J. Wei, Z. Sun, D. Zhao, Large-pore ordered mesoporous materials templated from non-Pluronic amphiphilic block copolymers., Chemical Society Reviews, 2013, 42, 4054-4070.

(60) Y. J. Cheng, J. S. Gutmann, Morphology phase diagram of ultrathin anatase TiO2 films templated by a single PS-b-PEO block copolymer, Journal of the American Chemical Society, 2006, 128, 4658-4674.

(61) J. Perlich, L. Schulz, M. M. Abu Kashem, Y. J. Cheng, M. Memesa, J. S. Gutmann, S. V. Roth, P. MullerBuschbaum, Modification of the morphology of P(S-b-EO) templated thin TiO2 films by swelling with PS homopolymer, Langmuir, 2007, 23, 10299-10306.

(62) Y.-J. Cheng, L. Zhi, W. Steffen, J. S. Gutmann, Surface-Supported, Highly Ordered Macroporous Crystalline $\mathrm{TiO} 2$ Thin Films Robust up to $1000 \hat{\mathrm{A}}^{\circ} \mathrm{C}$, Chemistry of Materials, 2008, 20, 6580-6582.

(63) J. Zhang, Y. Deng, D. Gu, S. Wang, L. She, R. Che, Z.-S. Wang, B. Tu, S. Xie, D. Zhao, Ligand-Assisted Assembly Approach to Synthesize Large-Pore Ordered Mesoporous Titania with Thermally Stable and Crystalline Framework, Advanced Energy Materials, 2011, 1, 241-248.

(64) Y. Li, W. Luo, N. Qin, J. Dong, J. Wei, W. Li, S. Feng, J. Chen, J. Xu, A. A. Elzatahry, M. H. Es-Saheb, Y. Deng, D. Zhao, Highly ordered mesoporous tungsten oxides with a large pore size and crystalline framework for H2S sensing., Angewandte Chemie International Edition, 2014, 53, 9035-9040.

(65) W. Luo, Y. Li, J. Dong, J. Wei, J. Xu, Y. Deng, D. Zhao, A resol-assisted co-assembly approach to crystalline mesoporous niobia spheres for electrochemical biosensing., Angewandte Chemie International Edition, 2013, 52, 10505-10510.

(66) J. Lee, M. C. Orilall, S. C. Warren, M. Kamperman, F. J. Disalvo, U. Wiesner, Direct access to thermally stable and highly crystalline mesoporous transition-metal oxides with uniform pores, Nature Materials, 2008, 7, 222228.

(67) B. C. Garcia, M. Kamperman, R. Ulrich, A. Jain, S. M. Gruner, U. Wiesner, Morphology Diagram of a Diblock Copolymer-Aluminosilicate Nanoparticle System, Chemistry of Materials, 2009, 21, 5397-5405.

(68) A. C. Finnefrock, R. Ulrich, A. Du Chesne, C. C. Honeker, K. Schumacher, K. K. Unger, S. M. Gruner, U. Wiesner, Metal oxide containing mesoporous silica with bicontinuous "Plumber's Nightmare" morphology from a block copolymer-hybrid mesophase, Angewandte Chemie-International Edition, 2001, 40, 1207-120+.

(69) A. C. Finnefrock, R. Ulrich, G. E. S. Toombes, S. M. Gruner, U. Wiesner, The plumber's nightmare: A new morphology in block copolymer-ceramic nanocomposites and mesoporous aluminosilicates, Journal of the American Chemical Society, 2003, 125, 13084-13093.

(70) A. Jain, G. E. S. Toombes, L. M. Hall, S. Mahajan, C. B. W. Garcia, W. Probst, S. M. Gruner, U. Wiesner, Direct access to bicontinuous skeletal inorganic plumber's nightmare networks from block copolymers, Angewandte Chemie-International Edition, 2005, 44, 1226-1229.

(71) G. E. S. Toombes, A. C. Finnefrock, M. W. Tate, R. Ulrich, U. Wiesner, S. M. Gruner, A re-evaluation of the morphology of a bicontinuous block copolymer-ceramic material, Macromolecules, 2007, 40, 8974-8982.

(72) M. Stefik, S. Mahajan, H. Sai, T. H. Epps, F. S. Bates, S. M. Gruner, F. J. DiSalvo, U. Wiesner, Ordered Threeand Five-ply Nanocomposites from ABC Block Terpolymer Microphase Separation with Niobia and Aluminosilicate Sols, Chemistry of Materials, 2009, 21, 5466-5473.

(73) J. Allgaier, A. Poppe, L. Willner, D. Richter, Synthesis and characterization of poly[1,4-isoprene-b-(ethylene oxide)] and poly[ethylene-co-propylene-b-(ethylene oxide)] block copolymers, Macromolecules, 1997, 30, 15821586.

(74) S. C. Warren, F. J. Disalvo, U. Wiesner, Nanoparticle-tuned assembly and disassembly of mesostructured silica hybrids, Nature Materials, 2007, 6, 156-161.

(75) M. Stefik, S. Wang, R. Hovden, H. Sai, M. W. Tate, D. A. Muller, U. Steiner, S. M. Gruner, U. Wiesner, Networked and chiral nanocomposites from ABC triblock terpolymer coassembly with transition metal oxide 
nanoparticles, Journal of Materials Chemistry, 2012, 22, 1078-1087.

(76) GreggS. J., SingK. S. W. Adsorption, Surface Area, \& Porosity, Second Edition; Academic Press: 1982;

(77) E. P. Barrett, L. G. Joyner, P. P. Halenda, The Determination of Pore Volume and Area Distributions in Porous Substances. I. Computations from Nitrogen Isotherms, Journal of the American Chemical Society, 1951, 73, 373380.

(78) J. Brandrup, E. H. Immergut, E. A. Grulke, Knovel, Polymer handbook, 1999,

(79) L. Chen, B. Yao, Y. Cao, K. Fan, Synthesis of well-ordered mesoporous titania with tunable phase content and high photoactivity, Journal of Physical Chemistry C, 2007, 111, 11849-11853.

(80) M. Arellano, I. Manas-Zloczower, D. L. Feke, Effect of surfactant treatment on the formation of bound polymer on titanium dioxide powders, Powder Technology, 1995, 84, 117-126.

(81) ManxzerL. E., DeatonJ., SharpP., SchrockR. R. 31. Tetrahydrofuran Complexes of Selected Early Transition Metals; John Wiley \& Sons, Inc.: 2007; pp 135-140.

(82) A. Choucair, A. Eisenberg, Control of amphiphilic block copolymer morphologies using solution conditions, European Physical Journal E, 2003, 10, 37-44.

(83) R. Lund, L. Willner, J. Stellbrink, A. Radulescu, D. Richter, Role of Interfacial Tension for the Structure of PEP-PEO Polymeric Micelles. A Combined SANS and Pendant Drop Tensiometry Investigation, Macromolecules, 2004, 37, 9984-9993.

(84) L. F. Zhang, A. Eisenberg, Multiple morphologies of crew-cut aggregates of polystyrene-b-poly(acrylic acid) block-copolymers, Science, 1995, 268, 1728-1731.

(85) L. F. Zhang, A. Eisenberg, Multiple morphologies and characteristics of "crew-cut" micelle-like aggregates of polystyrene-b-poly(acrylic acid) diblock copolymers in aqueous solutions, Journal of the American Chemical Society, 1996, 118, 3168-3181.

(86) Y. S. Yu, L. F. Zhang, A. Eisenberg, Multiple morphologies of crew cut aggregates of polybutadiene-bpoly(acrylic acid) diblocks with low T-g cores, Langmuir, 1997, 13, 2578-2581.

(87) T. Haliloglu, I. Bahar, B. Erman, W. L. Mattice, Mechanisms of the exchange of diblock copolymers between micelles at dynamic equilibrium, Macromolecules, 1996, 29, 4764-4771.

(88) A. Halperin, S. Alexander, Polymeric Micelles - Their Relaxation Kinetics, Macromolecules, 1989, 22, 24032412 .

(89) E. E. Dormidontova, Micellization kinetics in block copolymer solutions: Scaling model, Macromolecules, 1999, 32, 7630-7644.

(90) S. Creutz, J. vanStam, S. Antoun, F. C. DeSchryver, R. Jerome, Exchange of polymer molecules between block copolymer micelles studied by emission spectroscopy. A method for the quantification of unimer exchange rates, Macromolecules, 1997, 30, 4078-4083.

(91) K. Schillen, A. Yekta, S. R. Ni, M. A. Winnik, Characterization by fluorescence energy transfer of the core of polyisoprene-poly(methylmethacrylate) diblock copolymer micelles. Strong segregation in acetonitrile, Macromolecules, 1998, 31, 210-212.

(92) Y. Y. Won, H. T. Davis, F. S. Bates, Molecular exchange in PEO-PB micelles in water, Macromolecules, 2003, 36, 953-955.

(93) S. Jain, F. S. Bates, Consequences of nonergodicity in aqueous binary PEO-PB micellar dispersions, Macromolecules, 2004, 37, 1511-1523.

(94) A. G. Denkova, E. Mendes, M. O. Coppens, Non-equilibrium dynamics of block copolymer micelles in solution: recent insights and open questions, Soft Matter, 2010, 6, 2351-2357.

(95) R. C. Hayward, D. J. Pochan, Tailored Assemblies of Block Copolymers in Solution: It Is All about the Process, Macromolecules, 2010, 43, 3577-3584.

(96) T. Nicolai, O. Colombani, C. Chassenieux, Dynamic polymeric micelles versus frozen nanoparticles formed by block copolymers, Soft Matter, 2010, 6, 3111-3118.

(97) L. Willner, A. Poppe, J. Allgaier, M. Monkenbusch, D. Richter, Time-resolved SANS for the determination of unimer exchange kinetics in block copolymer micelles, Europhysics Letters, 2001, 55, 667-673.

(98) R. Lund, L. Willner, D. Richter, E. E. Dormidontova, Equilibrium chain exchange kinetics of diblock copolymer micelles: Tuning and logarithmic relaxation, Macromolecules, 2006, 39, 4566-4575.

(99) S. H. Choi, T. P. Lodge, F. S. Bates, Mechanism of Molecular Exchange in Diblock Copolymer Micelles: Hypersensitivity to Core Chain Length, Physical Review Letters, 2010, 104, 4.

(100) M. Klotz, P. A. Albouy, A. Ayral, C. Menager, D. Grosso, A. Van der Lee, V. Cabuil, F. Babonneau, C. Guizard, The true structure of hexagonal mesophase-templated silica films as revealed by X-ray scattering: Effects of thermal treatments and of nanoparticle seeding, Chemistry of Materials, 2000, 12, 1721-1728.

(101) J. Schuster, R. Kohn, A. Keilbach, M. Doblinger, H. Amenitsch, T. Bein, Two-Dimensional-Hexagonal Periodic Mesoporous Polymer Resin Thin Films by Soft Templating, Chemistry of Materials, 2009, 21, 5754-5762.

(102) D. Feng, W. Luo, J. Zhang, M. Xu, R. Zhang, H. Wu, Y. Lv, A. M. Asiri, S. B. Khan, M. M. Rahman, G. Zheng, D. Zhao, Multi-layered mesoporous TiO2 thin films with large pores and highly crystalline frameworks for efficient photoelectrochemical conversion, Journal of Materials Chemistry A, 2013, 1, 1591.

(103) S. Guldin, S. Hüttner, P. Tiwana, M. C. Orilall, B. Ülgüt, M. Stefik, P. Docampo, M. Kolle, G. Divitini, C. Ducati, S. A. T. Redfern, H. J. Snaith, U. Wiesner, D. Eder, U. Steiner, Improved conductivity in dye-sensitised solar cells through block-copolymer confined TiO2 crystallisation, Energy \& Environmental Science, 2010, 4, 
225.

(104) I. W. Hamley, V. Castelletto, Z. Yang, C. Price, C. Booth, Melt phase behavior of poly(oxyethylene)poly(oxypropylene) diblock copolymers, Macromolecules, 2001, 34, 4079-4081.

(105) G. Floudas, R. Ulrich, U. Wiesner, Microphase separation in poly(isoprene-b-ethylene oxide) diblock copolymer melts. I. Phase state and kinetics of the order-to-order transitions, Journal of Chemical Physics, 1999, 110, 652663.

(106) A. Thomas, H. Schlaad, B. Smarsly, M. Antonietti, Replication of lyotropic block copolymer mesophases into porous silica by nanocasting: Learning about finer details of polymer self-assembly, Langmuir, 2003, 19, 44554459.

(107) P. F. W. Simon, R. Ulrich, H. W. Spiess, U. Wiesner, Block copolymer-ceramic hybrid materials from organically modified ceramic precursors, Chemistry of Materials, 2001, 13, 3464-3486.

(108) X. Y. Liu, B. Z. Tian, C. Z. Yu, F. Gao, S. H. Xie, B. Tu, R. C. Che, L. M. Peng, D. Y. Zhao, Room-temperature synthesis in acidic media of large-pore three-dimensional bicontinuous mesoporous silica with Ia3d symmetry, Angewandte Chemie-International Edition, 2002, 41, 3876-3878.

\begin{tabular}{|c|c|c|c|}
\hline & $\begin{array}{l}\text { Pluronic } \\
\text { PEO- } b \text {-PPO- } \\
b \text {-PEO }\end{array}$ & $\begin{array}{c}\text { KLE } \\
\text { PHB- } b \text {-PEO }\end{array}$ & $\begin{array}{l}\text { IO } \\
\text { PI- } b \text {-PEO }\end{array}$ \\
\hline $\begin{array}{c}\text { Flory-Huggins } \\
\chi \text { at } 50^{\circ} \mathrm{C}\end{array}$ & $0.085^{104}$ & $\sim 0.33 *$ & $0.33^{105}$ \\
\hline Mn (kg/mol) & $2-13^{25}$ & $8-10^{106}$ & $10-84^{107}$ \\
\hline $\begin{array}{l}\text { wt\%PEO } \\
\text { Water / }\end{array}$ & $30-70 \%{ }^{25}$ & $37-57 \%{ }^{106}$ & $8-38 \%{ }^{107}$ \\
\hline $\begin{array}{l}\text { Alcohol } \\
\text { Soluble }\end{array}$ & Yes & Yes** & No \\
\hline $\begin{array}{c}\text { Hybrid } \\
\text { Morphologies }\end{array}$ & $\begin{array}{l}\mathrm{CM}, \mathrm{iH}, \mathrm{G} \\
\mathrm{L}^{39,108}\end{array}$ & $\mathrm{CM}^{106}$ & (i) $\mathrm{CM}, \underset{\mathrm{L}^{67}}{(\mathrm{i}) \mathrm{H}}, \mathrm{PN}, \mathrm{G}$, \\
\hline $\begin{array}{l}\text { Pore size } \\
\text { range }(\mathbf{n m}) * * *\end{array}$ & $5-10^{23}$ & $12-13^{106}$ & $11-50^{107}$ \\
\hline \multicolumn{4}{|c|}{$\begin{array}{l}\mathrm{CM}=\text { cubic packing of spherical micelles, } \mathrm{L}=\text { lamellar, } \mathrm{H}=\text { hexagonally } \\
\text { arranged cylinders, } \mathrm{G}=\text { double gyroid, } \mathrm{PN}=\text { plumber's nightmare }\end{array}$} \\
\hline \multicolumn{4}{|c|}{$*_{\chi}$ for KLE is similar to that for IO } \\
\hline \multicolumn{4}{|c|}{$\begin{array}{l}\text { **PHB and PI homopolymers are not soluble in water or alcohols, but } \\
\text { can be dispersed as aggregates in such solvents when of low molecular } \\
\text { weight and attached to a large fraction of PEO }\end{array}$} \\
\hline
\end{tabular}

Table II. Synthesis and characterization of PI- $b$-PEO block copolymers

\begin{tabular}{lccccc} 
& IO7K & IO13K & IO28K & IO41K & IO92K \\
\hline Overall $\mathbf{M}_{\mathbf{n}}, \mathbf{g} / \mathbf{m o l}$ & 6,787 & 12,500 & 27,975 & 40,981 & 91,900 \\
\multicolumn{1}{c}{$\mathbf{P I}, \mathbf{g} / \mathbf{m o l}$} & 4,410 & 9,948 & 20,230 & 30,121 & 63,227 \\
\multicolumn{1}{r}{$\mathbf{P E O}, \mathbf{g} / \mathbf{m o l}$} & 2,377 & 2,552 & 7,745 & 10,860 & 28,673 \\
$\mathbf{P D I}$ & 1.11 & 1.10 & 1.06 & 1.07 & 1.09 \\
$\chi \mathbf{N}^{\mathbf{a}}$ & 39.2 & 67.3 & 156.0 & 227.3 & 521 \\
$\mathbf{R}_{\mathbf{0}}$ of $\mathbf{P E O}^{\mathbf{b}}, \mathbf{n m}$ & 4.4 & 4.5 & 7.9 & 9.3 & 15.2
\end{tabular}

${ }^{\mathrm{a}} \chi \mathrm{N}$ was calculated using $\chi=65 / \mathrm{T}+0.125$.

${ }^{\mathrm{b}} \mathrm{R}_{\mathrm{o}}$ was calculated based on the equation, $\mathrm{R}_{0}=0.595 \sqrt{ } \mathrm{N}$. 


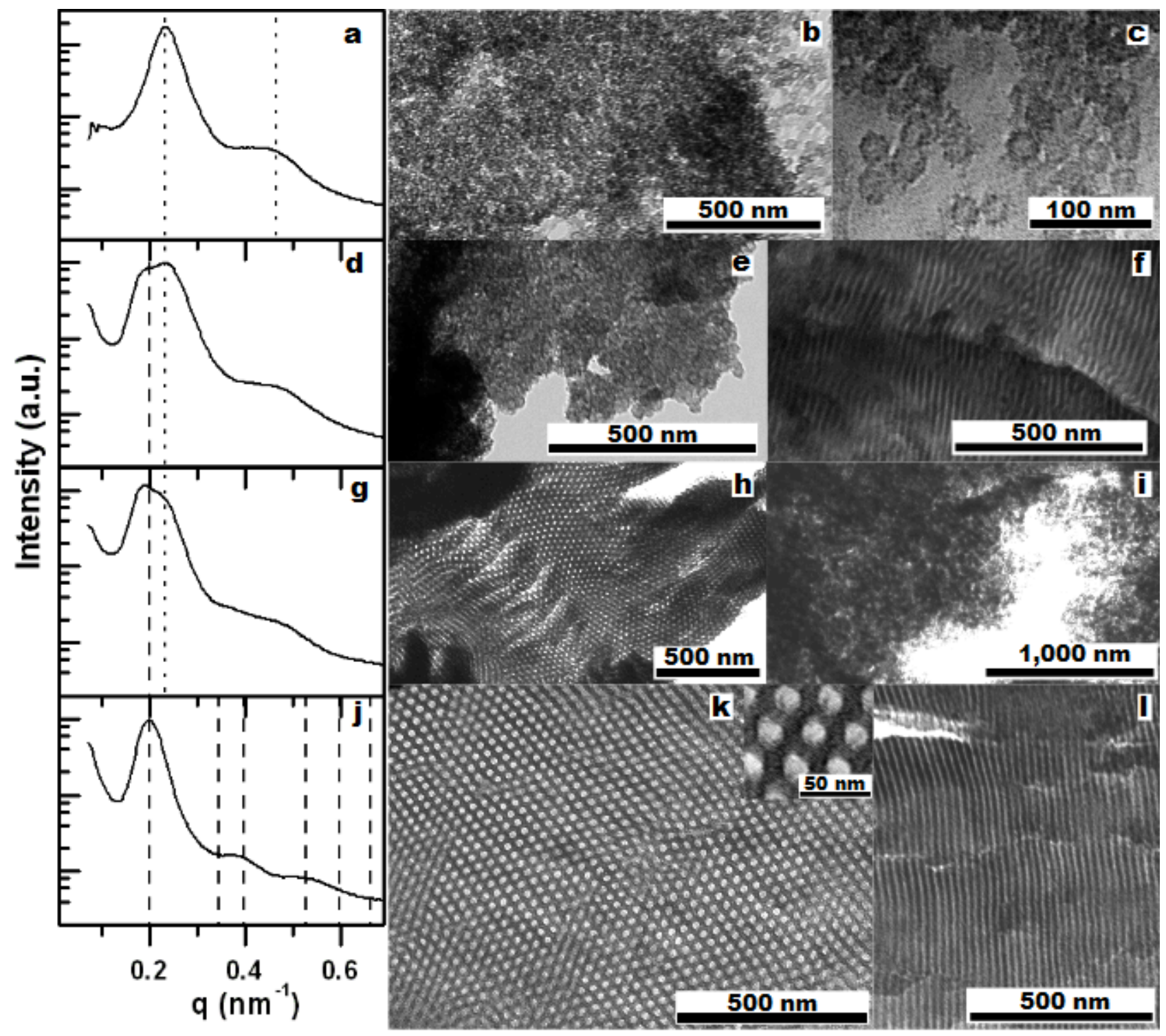

Figure 1. The SAXS patterns for samples IO28K-h4 (a), IO28K-h3 (d), IO28K-h2 (g), and IO28K-h1 (j) indexed with a random micellar lattice (dots), a hexagonal lattice (dashes), or a mixture of the two. Bright field TEM images of IO28Kh4 (b,c), IO28K-h3 (e,f), IO28K-h2 (h,i), and IO28K-h1 (k,l) are consistent with inverse spherical micelles (iSM), inverse hexagonally arranged cylinders $(\mathrm{iH})$, or a mixture of the two. The $\mathrm{iH}$ samples were indexed as $\mathrm{q} / \mathrm{q}^{*}=1, \sqrt{3}, \sqrt{4}$, $\sqrt{ } 7, \sqrt{ } 9, \sqrt{ } 12$ where $q$ is defined as $q=4 \pi \sin \theta / \lambda$. The data are presented as rows for each sample descending in order of increasing water content. 

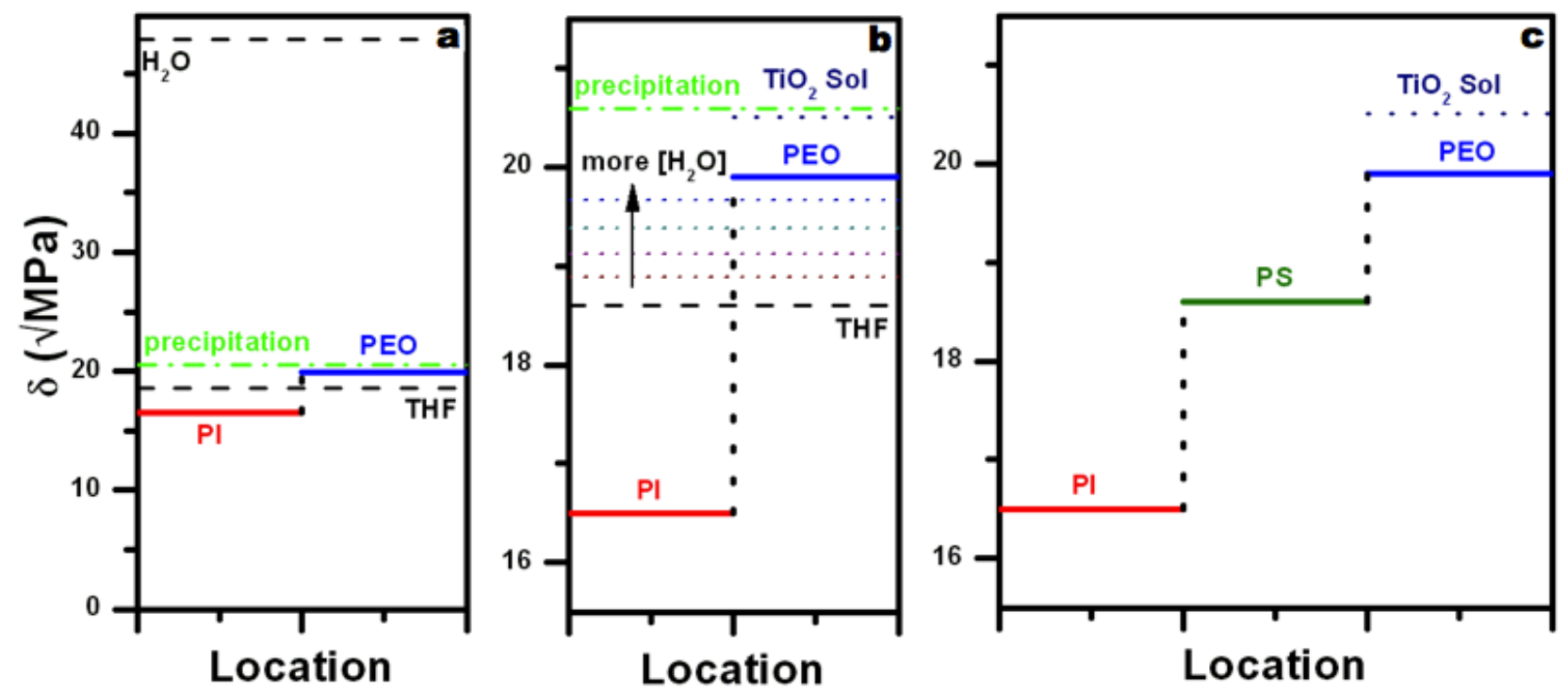

Figure 2. Plots of Hildebrand solubility parameters indicating the relative strength of intermolecular interactions and facilitating the prediction of miscibility. Though water is a precipitation agent for many polymers its use is required for numerous hydrolytic sol-gel procedures (a). Samples IO28K-h1, IO28K-h2, IO28K-h3, and IO28K-h4 were prepared with increasing initial water concentrations (b) leading to strikingly different morphologies (compare to Figure 1). Successful coassembly with more complex triblock terpolymer structure directing agents requires attention to the solubility of all four species involved (c). 

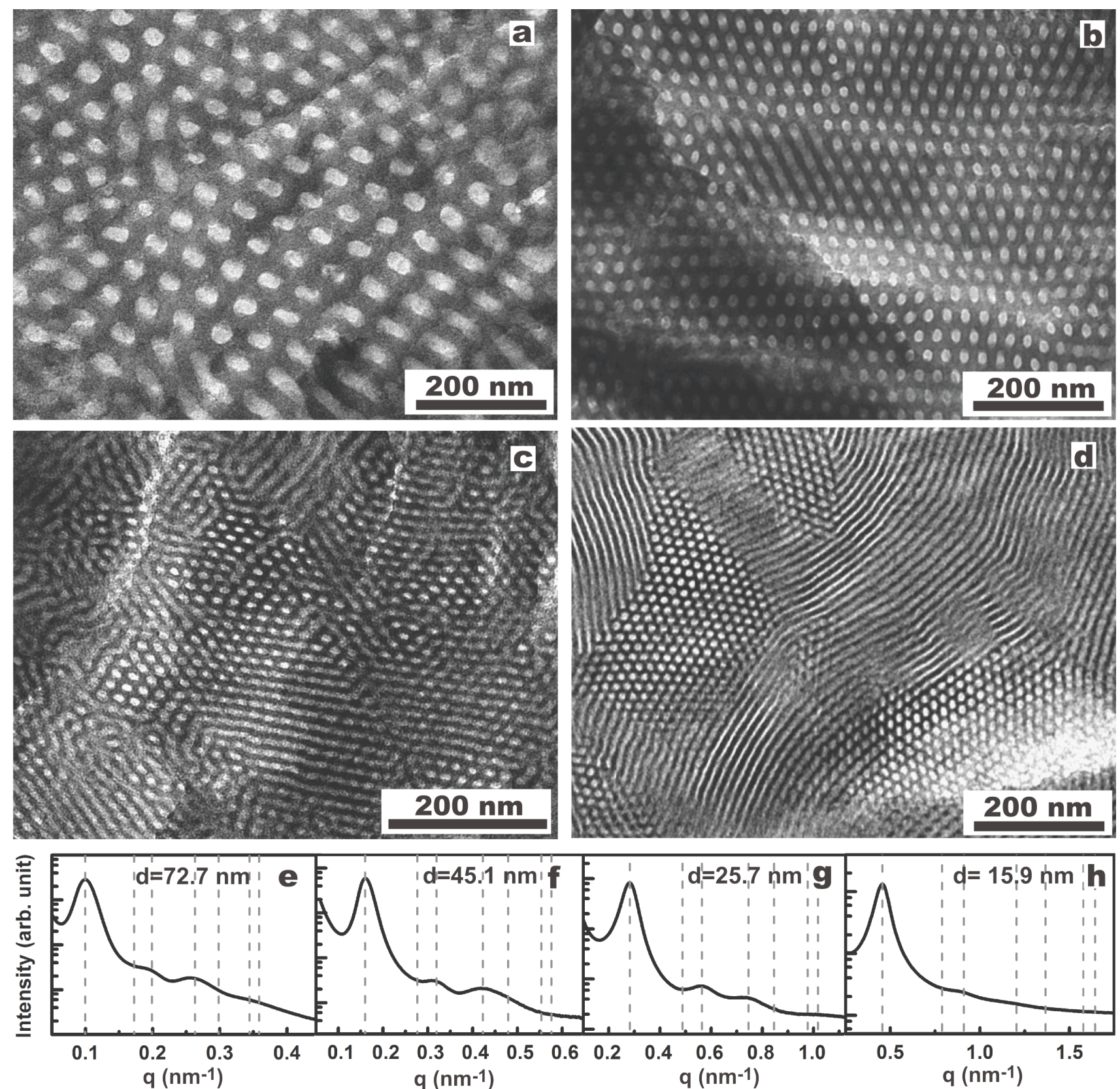

Figure 3. Bright field TEM images and SAXS patterns for BCP/titania hybrid samples: IO92K-h $(\mathrm{a}, \mathrm{e}), \mathrm{IO} 41 \mathrm{~K}-\mathrm{h}(\mathrm{b}, \mathrm{f}), \mathrm{IO} 13 \mathrm{~K}-\mathrm{h}(\mathrm{c}, \mathrm{g})$ and IO7K-h $(\mathrm{d}, \mathrm{h})$. The SAXS patterns are indexed with a hexagonal lattice. The cylinder-to-cylinder spacing from SAXS measurements were calculated from $\mathrm{d}=4 \pi /\left(\mathrm{q}^{*} \sqrt{3}\right)$ where $\mathrm{q}^{*}$ corresponds to each primary peak. 

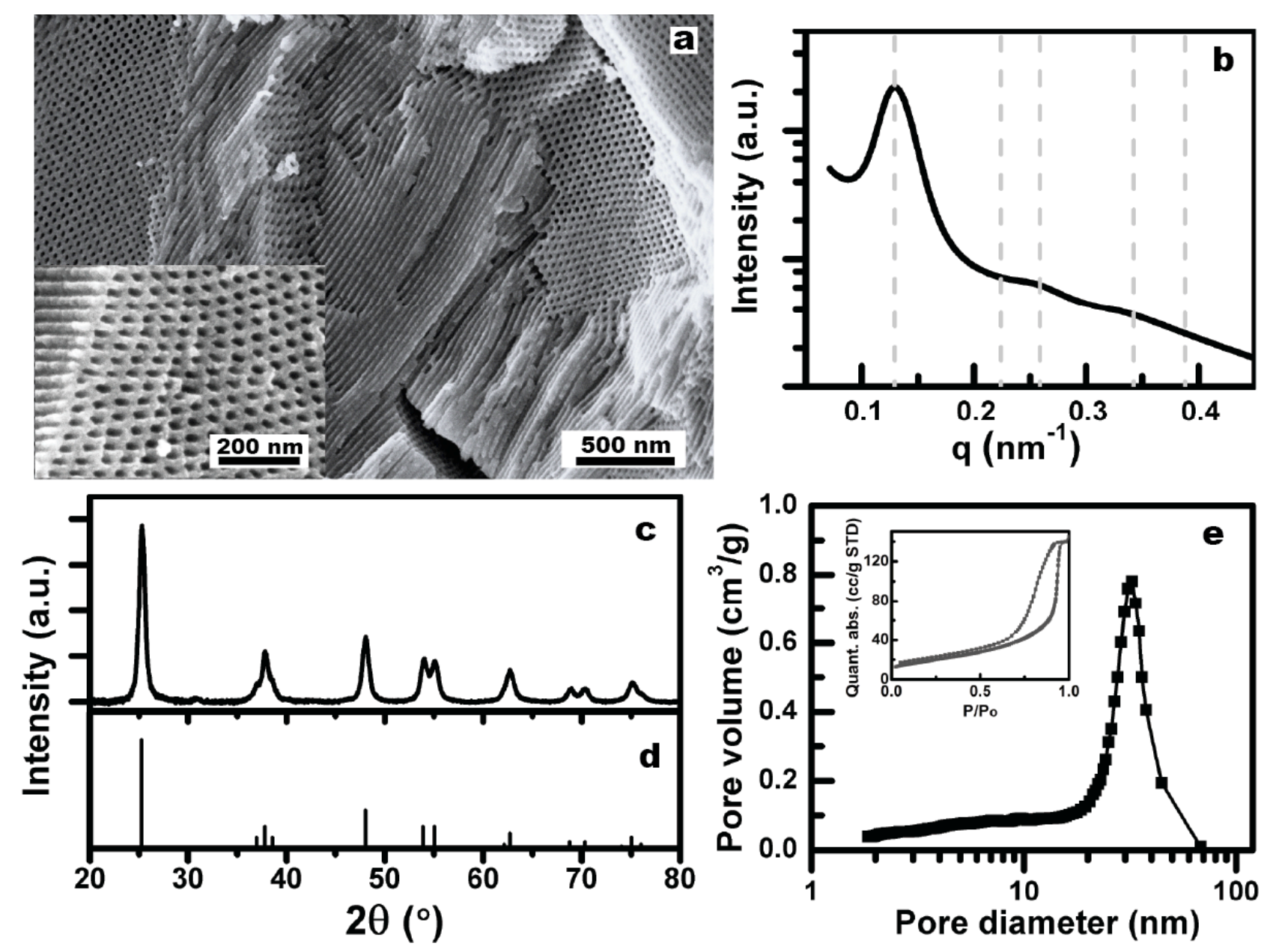

Figure 4. The ordered mesostructure of IO92K-CASH after the first calcinations in inert atmosphere followed by the subsequent calcination in air is confirmed by SEM (a) and SAXS (b). The cylinderto-cylinder spacing from SAXS was calculated as $56.0 \mathrm{~nm}$. XRD analysis indicates that the mesoporous titania is highly crystalline (c), with peak assignments consistent with anatase titania (d, PDF\#21-1272). Nitrogen physisorption measurements and analysis confirm that this sample is mesoporous with a narrow BJH pore size distribution and average pore size of $32.3 \mathrm{~nm}(\mathrm{e})$. 
Table III. Summary of structure characteristics of PI- $b$-PEO derived hybrids and mesoporous titania

\begin{tabular}{|c|c|c|c|c|c|}
\hline $\mathrm{BCP} /$ titania hybrids & IO7K-h & IO13K-h & $I^{028 K-h^{a}}$ & IO41K-h & IO92K-h \\
\hline $\begin{array}{l}\text { SAXS cylinder-to- } \\
\text { cylinder spacing, nm }\end{array}$ & 15.9 & 25.7 & 36.4 & 45.1 & 72.7 \\
\hline Mesoporous titania & $\begin{array}{l}\text { IO7K- } \\
\text { CASH } \\
\end{array}$ & $\begin{array}{c}\text { IO13K- } \\
\text { CASH } \\
\end{array}$ & $\begin{array}{c}\text { IO28K- } \\
\text { CASH }\end{array}$ & $\begin{array}{c}\text { IO41K- } \\
\text { CASH } \\
\end{array}$ & $\begin{array}{c}\text { IO92K- } \\
\text { CASH } \\
\end{array}$ \\
\hline Pore size ${ }^{\mathrm{b}}, \mathrm{nm}$ & 8.9 & 11.4 & 16.1 & 19.2 & 32.3 \\
\hline $\begin{array}{l}\text { Surface area }{ }^{\mathrm{c}} \text {, } \\
\mathrm{m}^{2} / \mathrm{g}\end{array}$ & 70.0 & 84.9 & 82.4 & 69.2 & 64.1 \\
\hline
\end{tabular}

${ }^{\text {a }}$ Inorganic/organic ratio (2.0) is slightly smaller than the other materials (2.15).

${ }^{\mathrm{b}}$ Pore size is determined from the peak value of the BJH adsorption derived pore size distribution and ${ }^{\mathrm{c}}$ surface area is obtained from BET analysis of nitrogen adsorption-desorption data.

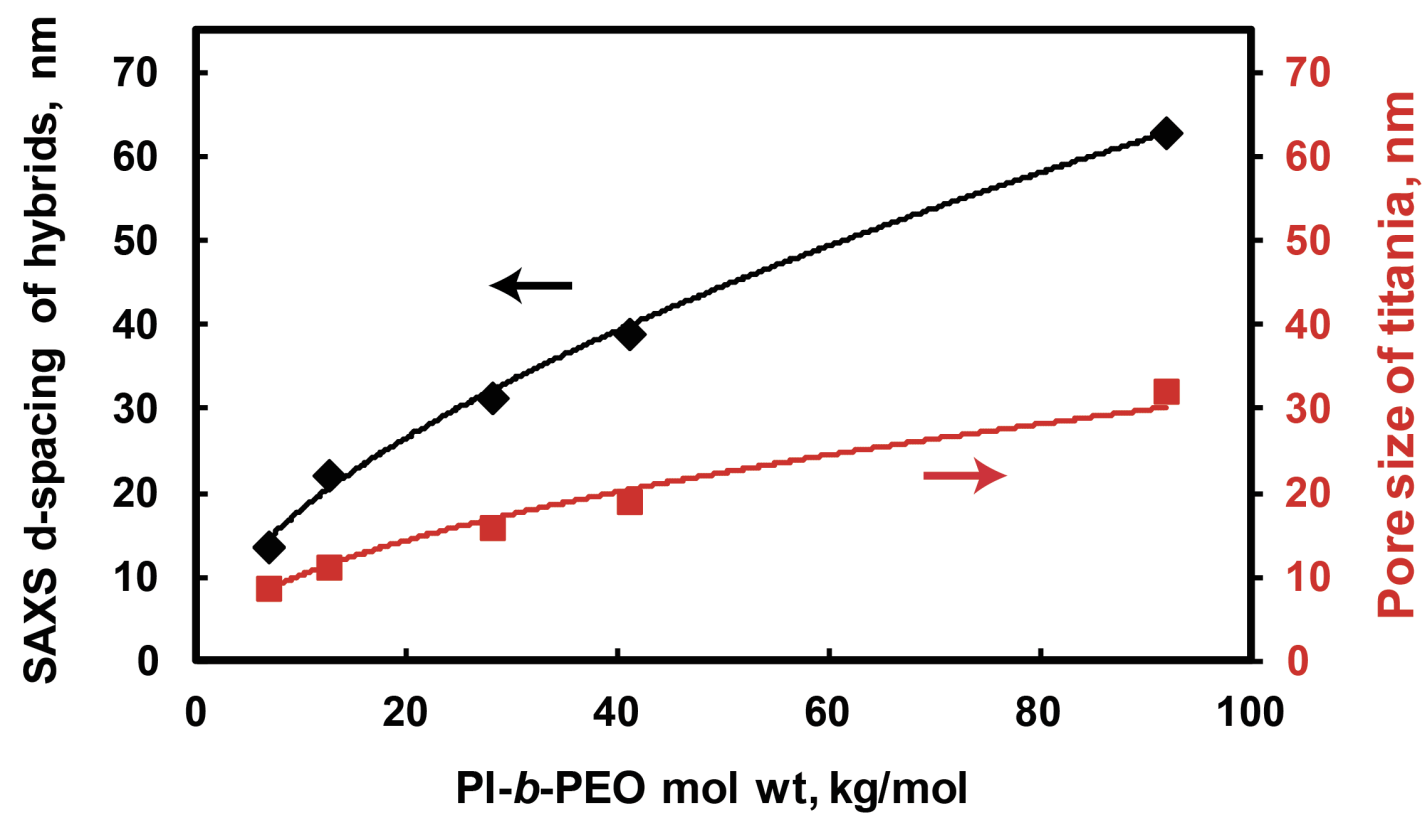

Figure 5. Dependence of d-spacings obtained from SAXS and BJH derived pore sizes on PI- $b$-PEO molar mass for titania/PI- $b$-PEO hybrids and resulting mesoporous crystalline titania, respectively. The $\mathrm{d}$-spacing was calculated as $\mathrm{d}=2 \pi / \mathrm{q}^{*}$. 

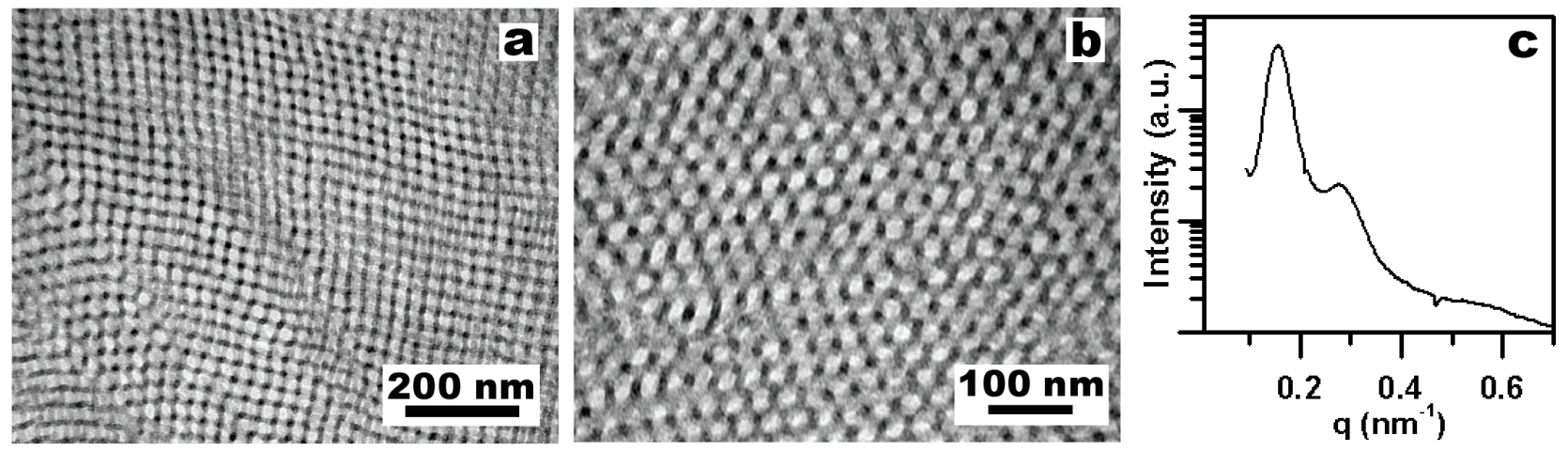

Figure 6. Bright field TEM images of microtomed sections of $\mathrm{ISO}^{-}-\mathrm{TiO}_{2}$ showing four-fold (a) and three-fold projections (b), consistent with a cubic network morphology. The broad SAXS pattern for ISO1-TiO 2 (c) is similar to a previously reported pattern for networked hybrids derived from the same ISO1 polymer and niobia. 

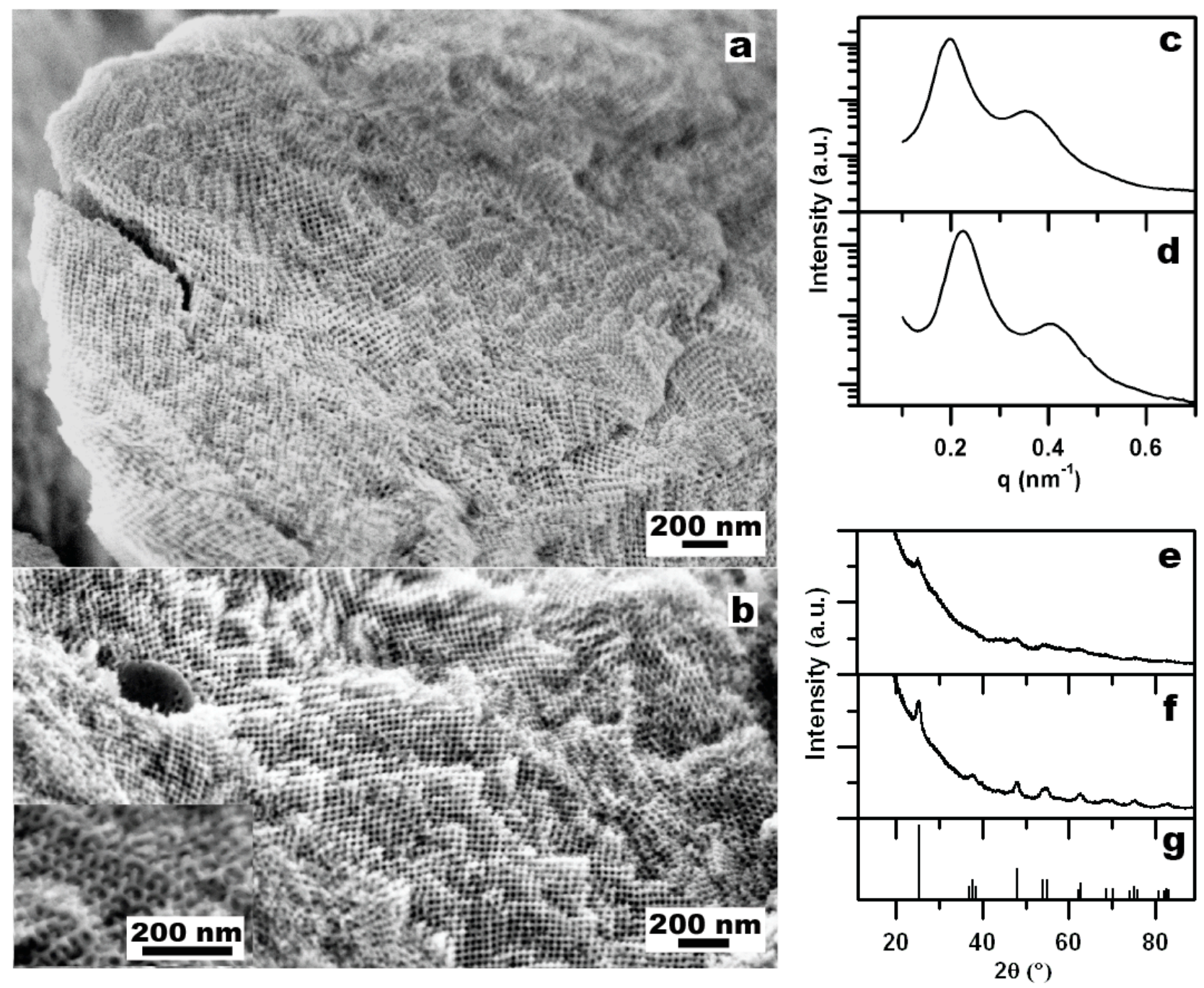

Figure 7. Sample ISO1- $\mathrm{TiO}_{2}$ with ordered network mesostructure was calcined at lower temperatures to avoid structural collapse. The mesostructure was preserved after calcination in inert atmosphere as evidenced by SEM (a) and SAXS (c), however, according to XRD (e) the resulting titania is only slightly crystalline. Calcination of $\mathrm{ISO}_{\mathrm{S}}-\mathrm{TiO}_{2}$ directly in air results in similar structural preservation as evidenced by SEM (b) and SAXS (d), but results in a greater extent of anatase crystallization as measured by XRD $(\mathrm{f}, \mathrm{g})$. 